\title{
Un modelo para el análisis de la integración sociolingüística de la población migrante: fundamentos, dimensiones e instrumentos
}

\section{Florentino Paredes García}

El crecimiento imparable de la migración en el mundo actual, especialmente la de carácter internacional, hace obligado atender a las consecuencias de esos movimientos de población y, en particular, conocer cómo se produce el complejo proceso de integración entre los grupos sociales que entran en contacto. La lengua o las variedades lingüísticas de esos grupos son uno de los elementos claves en este sentido, por lo que la sociolingüística de la migración se ha centrado especialmente en entender qué papel desempeña lo lingüístico y lo comunicativo, en aras de poder favorecer ese proceso. Este artículo persigue tres objetivos: 1) describir las bases teóricas que fundamentan el análisis de las situaciones de contacto lingüístico producido por la migración; 2) analizar las dimensiones que han de abordarse en el estudio de la integración sociolingüística; y 3) presentar instrumentos que posibiliten el análisis global de estas dimensiones; en concreto, se ofrecen los recursos empleados en el proyecto de investigación IN.MIGRA-CM: la entrevista sociolingüística basada en relatos de vida y los cuestionarios bidireccionales de actitudes hacia la inmigración y las variedades lingüísticas.

Palabras claves: Integración sociolingüística, aculturación, actitudes lingüísticas, proyecto INMIGRA-CM Comunidad de Madrid, entrevista sociolingüística.

A Model for Analyzing the Sociolinguistic Integration of the Migrant Population: Foundations, Dimensions, and Instruments. The unstoppable growth in migration in today's world, especially international migration, means we must confront the consequences of these population movements and, in particular, understand the complex process of integration that takes place between social groups that come into contact. These groups' languages or linguistic varieties are a key ele- 
ment in this regard, and therefore the sociolinguistics of migration has particularly focused on understanding the role played by linguistic and communicative aspects, in the interest of facilitating this process. This article has three objectives: 1) describe the theoretical foundations behind the analysis of situations of language contact caused by migration; 2) analyze the aspects that must be considered when studying sociolinguistic integration; and 3) present instruments that facilitate the comprehensive analysis of these aspects; specifically, the resources employed in the INMIGRA-CM research project are offered: sociolinguistic interviews based on life experiences and bidirectional questionnaires on attitudes toward immigration and linguistic varieties.

Keywords: Sociolinguistic integration, acculturation, linguistic attitudes, INMIGRA-CM Community of Madrid Project, sociolinguistic interview.

\section{Introducción ${ }^{1}$}

La migración, que hunde sus raíces en la historia $-\mathrm{y}$ de hecho puede considerarse inherente a la condición humana-, ha alcanzado durante el siglo XX y el siglo XXI unas cotas desconocidas en épocas pasadas, tanto en términos cuantitativos como proporcionales, y todo indica que avanza a un ritmo elevado, mayor incluso que el previsto. En las sociedades desarrolladas actuales ha pasado a ser un fenómeno estructural, que ha de vincularse con el desarrollo de la globalización (Retortillo 2009: 74). Según el Informe sobre las migraciones en el mundo 2018 (McAuliffe y Rufs 2018), la migración nacional afectó a 740 millones de personas, que se han desplazado dentro de su propio país de nacimiento, mientras que la inmigración internacional afectó a 244 millones de personas. No obstante, el ritmo de avance de esta segunda ha cobrado mayor relieve: si en 1970 el número de migrantes internacionales era de 84,5 millones de personas (2,3\%), en 2015 la cifra se multiplicó por tres hasta alcanzar los 244 millones, lo que supone el 3,3\% de la población mundial (1 de cada 30 personas migra a otro país). ${ }^{2}$

En España la situación ha corrido una suerte similar en lo que concierne a la inmigración nacional, pero en los últimos 30 años ha visto surgir un tipo de movimiento poblacional al que no estaba habituada históricamente la población española: la migración internacional. Durante el siglo XX se produjeron en el país dos grandes oleadas migratorias. La primera, de carácter interno, tuvo lugar sobre todo entre las décadas del 60 y el 90 y tuvo su origen en el Plan de estabilización europeo de 1960, plan que provocó un movimiento demográfico único en Europa que hizo que cada año cambiasen de región en torno a un cuar-

Lengua y migración / Language and Migration 12:1 (2020) Monográfico, 39-81

Edición impresa: ISSN 1889-5425. Edición en línea: ISSN 2660-7166. C Universidad de Alcalá 
to de millón de personas (Paredes y Molina 2019). ${ }^{3}$ La segunda oleada migratoria, la inmigración extranjera, cobra relieve en la década de los 90 y crece exponencialmente hasta 2008. Probablemente el aspecto más relevante es que España ha pasado, en muy pocos años, de ser un país de emigración ${ }^{4}$ a convertirse en uno de los países receptores más importantes del mundo en términos proporcionales: la población extranjera en España ha crecido desde prácticamente cero en 1990 hasta el 12,5\% en 2009 (Portes, Aparicio y Haller 2018), cifra comparable a la del 13\% de Estados Unidos, con la diferencia de que allí la inmigración ha estado ocurriendo durante todo el siglo XX al menos. Por primera vez en la historia, España recibe grupos importantes de inmigrantes procedentes de Latinoamérica, de Europa del Este, del Magreb, del África Subsahariana o de Asia (Paredes García 2019).

Población extranjera por Nacionalidad, provincias, Sexo y Año. Estadística del Padrón Continuo, TOTAL EXTRANJEROS, TOTAL ESPAÑA, Ambos sexos

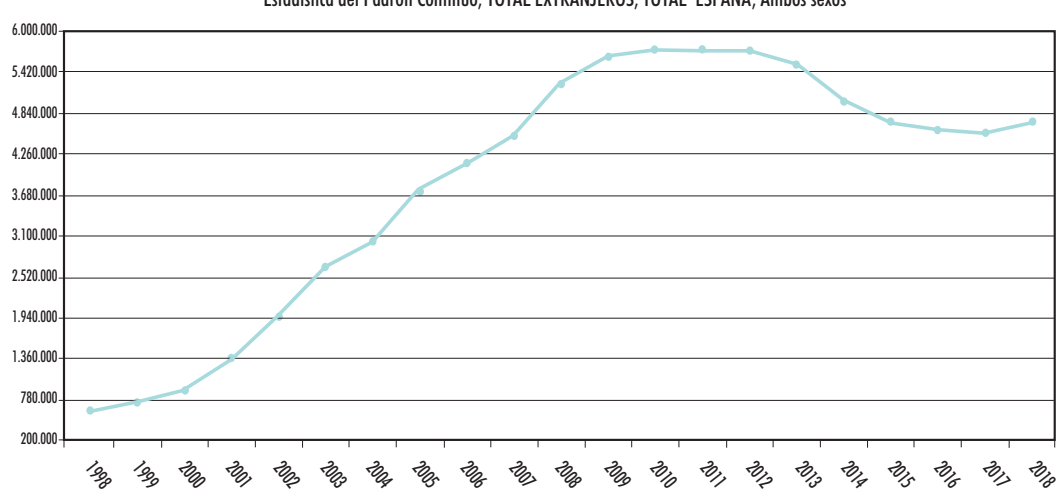

Gráfico 1. Evolución de la población extranjera en España entre 1998 y 2018 (Fuente: INE)

En los últimos años la evolución de la inmigración en España ofrece un perfil fluctuante que mantiene un ritmo acompasado a la situación socioeconómica española, europea y mundial. Si atendemos a las estadísticas del INE (2014) o los estudios realizados por el colectivo Ioé (Colectivo Ioé 2010), tras una década larga de tendencia al aumento en el número de inmigrantes, la curva muestra entre los años 2013 y 2017 una inflexión, un decrecimiento en el ritmo de llegada de extranjeros, que con bastante probabilidad es meramente circunstancial y parece estar revirtiendo en la medida en que la coyuntura económica española va siendo más favorable (Paredes García 2019).

Diversos estudios han llamado la atención sobre la particular situación de España en relación con la inmigración. La crisis económica vivida a partir de 2008 hacía suponer un aumento de las actitudes xenófobas que, sin embargo, no ha llegado a producirse (Arango 2013, Rinken 2015). Según 
los últimos informes del Observatorio Permanente de la Inmigración, la visión de los inmigrantes por parte de los españoles se declara como positiva y, en concreto, es en la Comunidad de Madrid donde se dan unos índices más altos de aceptación (Godenau, Rinken, Martínez de Lizarrondo y Moreno 2014: 146 y 2017: 122-125). Ello no obsta para que surjan problemas específicos relacionados con la convivencia entre grupos y que las opiniones expresadas abiertamente puedan ocultar un trasfondo de actitudes menos favorables, más difíciles de manifestarse abiertamente.

En relación con la lengua, la migración internacional ha supuesto algunos cambios de relieve en la sociedad española. Por poner solo un ejemplo, la presencia de población migrante ha dado lugar a que en territorios en tradicionalmente monolingües, pongamos por caso una ciudad como Alcalá de Henares, sea absolutamente normal hoy encontrar muestras de lenguas diversas en el paisaje lingüístico de la ciudad (Figura 1).

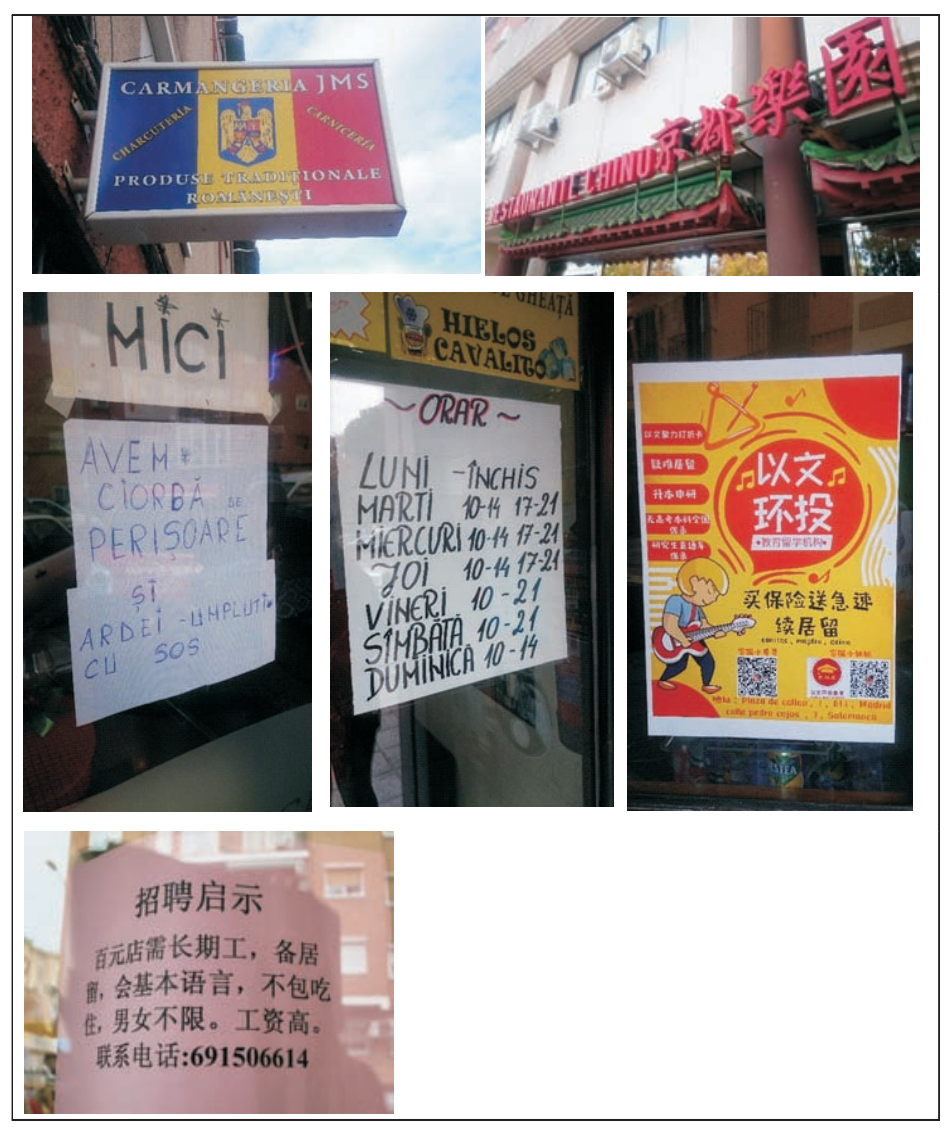

Figura 1. Imágenes del paisaje lingüistico de Alcalá de Henares a finales de $2018 .^{5}$

Lengua y migración / Language and Migration 12:1 (2020) Monográfico, 39-81 Edición impresa: ISSN 1889-5425. Edición en línea: ISSN 2660-7166. @ Universidad de Alcalá 
Los trabajos sobre el paisaje lingüístico de la ciudad de Madrid (Castillo Lluch y Sáez Rivera 2011, 2012; Saiz de Lobado 2016) documentan la presencia y distribución de las lenguas foráneas en la capital. Castillo Lluch y Sáez Rivera ordenan del siguiente modo las 34 lenguas escritas que encuentran en las calles madrileñas: chino, inglés, francés, árabe, italiano, japonés, alemán, latín, catalán, gallego, portugués, rumano, hindi, tagalo, bengalí, guaraní, ruso, euskera, hebreo, amárico, hawaiano, polaco, curdo, asturiano, aimara, quechua, armenio, griego, búlgaro, ucraniano, persa, wólof, turco y tailandés. Estas lenguas no se distribuyen homogéneamente sobre el espacio urbano, sino que obedecen a diferentes patrones que pueden ser reflejo de la situación sociolingüística en el territorio madrileño. ${ }^{6}$ Habrá que analizar el efecto que este paisaje tiene sobre la variedad autóctona, pero sin duda la presencia pública, de las nuevas lenguas y variedades lingüísticas, y no solo de la vertiente escrita, ha de ejercer influencia sobre las actitudes de la población autóctona, ya sea de forma abierta, ya sea de manera latente.

Los procesos migratorios, en definitiva, son tan relevantes en el mundo actual que el interés por conocer su complejidad poliédrica ha atraído a numerosos investigadores de diversas disciplinas, que se han acercado al fenómeno con perspectivas y métodos también diversos. Dentro del ámbito de la lingüística se ha propuesto incluso la necesidad de una disciplina específica destinada a estudiar las relaciones entre migración y lengua. Ha tenido cierta difusión la denominación Lingüística de la migración (Zimmerman y Morgenthaler García 2007) ${ }^{7}$ cuyo objeto sería determinar los efectos de la migración sobre la lengua y la comunicación entre los grupos migrantes y los de la sociedad receptora.

En este sentido, cabe hablar de una sociolingüística de la migración cuyo objeto sería aplicar los principios y métodos de la sociolingüística a las situaciones de contacto producidas por los movimientos migratorios. La finalidad última de esta sociolingüística, sin embargo, trascendería los límites de la mera investigación científica y debería encaminarse al logro de una sociedad más inclusiva, más solidaria y más humana (Moreno Fernández 2009: 153). Siguiendo los principios metodológicos de la sociolingüística, la disciplina ha de tomar como objeto de análisis el estudio de una comunidad de habla, dado que solo en el seno de esta es posible determinar el significado social asociado a los usos lingüísticos y comunicativos. ${ }^{8}$ Entre las tareas básicas de la sociolingüística de la migración estaría la recopilación de muestras reales de la(s) lengua(s) hablada(s) (y, complementariamente escrita u otros tipos de manifestaciones comunicativas) que permitan, por una parte, describir los repertorios lingüísticos de los grupos poblacionales de ambas sociedades y, por otra, analizar contrastivamente los usos lingüísticos respectivos. Los 
objetivos del estudio de la integración sociolingüística de la migración, en definitiva, se pueden resumir en los siguientes:

1. Identificar los factores que pueden influir en el proceso de integración, atendiendo especialmente al grado en que afecta y se ve afectado el componente lingüístico y comunicativo.

2. Identificar las percepciones, creencias y actitudes de los inmigrantes hacia la sociedad receptora y hacia la variedad o variedades lingüísticas, así como las de la población receptora hacia los grupos de inmigrantes y sus variedades lingüísticas.

3. Describir las estrategias de aculturación desarrolladas por los inmigrantes grupal o individualmente y compararlas con las seguidas por la población de la sociedad receptora.

4. Determinar, mediante análisis que combinen lo cuantitativo y lo cualitativo, en qué medida los aspectos lingüísticos y comunicativos, por una parte, son reflejo del grado de integración de los grupos o de los individuos y, por otra, condicionan favorable o desfavorablemente el proceso. En este sentido, un objetivo central habría de ser identificar los aspectos que puedan resultar más problemáticos y que dificulten la integración.

5. En una dimensión aplicada de la sociolingüística de la migración, proponer pautas y actuaciones (políticas, sociales, culturales) para favorecer el proceso de integración y elaborar herramientas e instrumentos que lo posibiliten.

Este artículo es una reflexión sobre los fundamentos teóricos y metodológicos que deben regir el estudio de la integración sociolingüística de la población migrante y, más específicamente, describe las pautas y algunos resultados alcanzados dentro de la red INMIGRA-CM, que ha obtenido varios proyectos de investigación financiados por la Comunidad de Madrid y por el Fondo Social Europeo.

\section{Bases teóricas para el estudio de la integración sociolingüística de la población migrante}

La complejidad del proceso de integración sociolingüística exige un planteamiento multidisciplinar a la hora de abordarlo (Moreno Fernández 2009). Aunque son muchos los conceptos y presupuestos que se han de manejar en el análisis de la integración sociolingüística,

Lengua y migración / Language and Migration 12:1 (2020) Monográfico, 39-81

Edición impresa: ISSN 1889-5425. Edición en línea: ISSN 2660-7166. @ Universidad de Alcalá 
nos centraremos en los que consideramos más relevantes para entender el fenómeno desde la perspectiva que aquí interesa. Son los siguientes: las teorías de la aculturación, propugnadas por Berry $(1997,2001,2005)$ y ampliadas posteriormente por Bourhis y otros (1997), que consideran el carácter bidireccional del proceso y toman en cuenta las estrategias que los grupos poblacionales y los individuos pueden adoptar en función de sus deseos de preservar sus rasgos identitarios o relacionarse con la sociedad receptora; las teorías de la identidad social y de la autocategorización del yo, planteadas por Tajfel $(1974,1978,1981)$ y Turner (1982), que consideran que la identidad de un individuo se define conjuntamente por sus relaciones de pertenencia a un grupo y por las relaciones interpersonales con otros individuos y, por otro lado, intentan explicar el hecho de que un mismo individuo pueda desarrollar identidades diversas ante las situaciones; la teoría de la acomodación comunicativa, de Bourhis y Giles (1977), que explican los procesos de convergencia o divergencia que tienen lugar en las situaciones de comunicación cara a cara; los aportes de los estudios sobre las lenguas en contacto, especialmente las que se refieren a los procesos de creación de interlengua e interdialecto. En cuanto al desarrollo del proceso de integración, resulta explicativo el modelo piramidal, de Moreno Fernández (2009), que interpreta la integración como un proceso gradual, dinámico y mensurable, en el que integración social e integración sociolingüística van en paralelo y atraviesan diferentes fases, en las cuales se ven afectados en diverso grado el plano lingüístico y el comunicativo.

\subsection{Teorías de la aculturación}

Desde la sociología, uno de los modelos más influyentes en el estudio de la incorporación de los inmigrantes a las sociedades receptoras es el modelo de aculturación, desarrollado en la década de los 80 por John W. Berry en varios trabajos $(1997,2001,2005)$. Este modelo se basa en las relaciones intergrupales de las sociedades en las que tienen lugar procesos migratorios, entendiendo la aculturación como un proceso dual:

Acculturation is the dual process of cultural and psychological change that takes place as a result of contact between two or more cultural groups and their individual members. At the group level, it involves changes in social structures and institutions and in cultural practices. At the individual level, it involves changes in a person's behavioral repertoire (Berry, 2005: 698-699).

Las relaciones que se establecen entre los dos grupos, el alóctono y el autóctono, vienen determinadas por el mayor o menor grado en que, por 
un lado, cada grupo o cada individuo pretende mantener la propia identidad y cultura y, por otro, en qué medida cada grupo busca el contacto con los otros grupos (Figura 2). Combinando ambas dimensiones, dentro del grupo migrante o grupo subordinado pueden identificarse cuatro posibles estrategias de aculturación: (1) integración, si el grupo subordinado considera básico mantener la identidad y la cultura propias pero a la vez está abierto a las relaciones con la sociedad receptora; (2) asimilación, si se prima abandonar la propia identidad cultural y se opta por establecer relaciones con los grupos de la sociedad receptora; (3) separación, cuando el grupo dominado pretende ante todo preservar su identidad y sus características culturales, evitando relaciones con la sociedad receptora; y (4) marginalización, si los grupos minoritarios simultáneamente pierden su identidad cultural y evitan relaciones con la sociedad receptora.

Paralelamente, en la sociedad receptora o grupo dominante pueden encontrarse también cuatro estrategias aculturativas: (1) multiculturalismo, si el grupo dominante acepta la diversidad cultural a través del contacto con los nuevos habitantes; (2) melting pot (o crisol mestizo), si el grupo dominante favorece procesos de interacción sin pretender mantener en exclusiva su identidad cultural; (3) segregación, cuando el grupo mayoritario tolera que los inmigrantes mantengan sus características, pero rechaza relaciones estrechas con ellos; y (4) exclusión, cuando el grupo dominante fuerza la pérdida de contacto del grupo minoritario con su cultura de origen y rechaza también las relaciones con los grupos de la sociedad receptora.

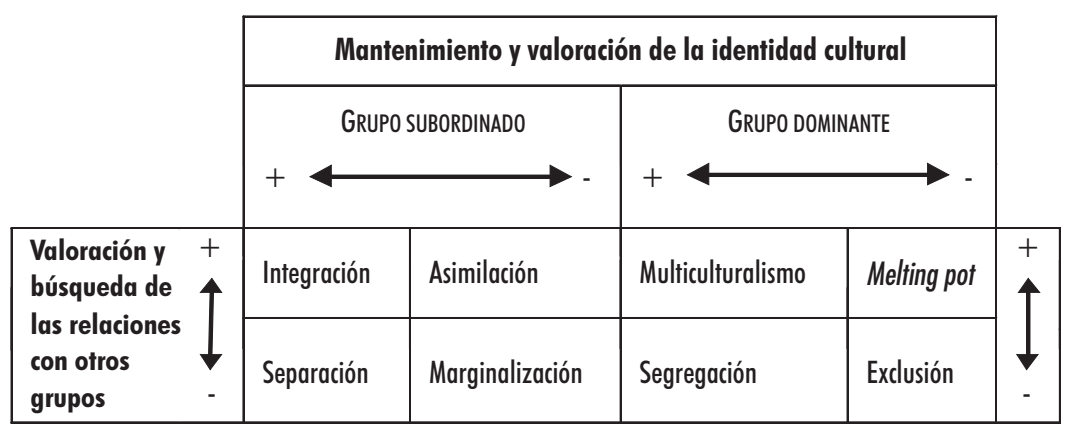

Figura 2. Estrategias de aculturación (elaborado a partir de Berry 2005:705).

El modelo ha recibido algunas críticas (Scandroglio, López y San José 2008; García Vázquez 2008), entre ellas la de no reflejar adecuadamente la asimetría de las relaciones de poder entre los grupos en contacto. De hecho, la posibilidad de que haya una efectiva integración no se produce solo por la voluntad de la población migrante: la integración solo es posible si en la sociedad de acogida se adoptan actitudes y estrategias que propician la multiculturalidad, es decir, la tolerancia hacia la

Lengua y migración / Language and Migration 12:1 (2020) Monográfico, 39-81

Edición impresa: ISSN 1889-5425. Edición en línea: ISSN 2660-7166. @ Universidad de Alcalá 
ideología multicultural, la ausencia de prejuicios étnicos y las actitudes positivas entre los grupos culturales.

También se ha puesto de relieve el escaso papel que el modelo otorga al individuo. En este sentido, Bourhis, Möise, Perreault y Senécal (1997), en su Modelo Interactivo de Aculturación, identifican una nueva estrategia de aculturación: la del individualismo. Esta estrategia supone que los miembros del grupo inmigrante o de la sociedad de acogida pueden valorar las características individuales por encima de la pertenencia al grupo, de manera que las interrelaciones se producen independientemente de esa pertenencia al grupo, minimizando la importancia del mantenimiento de la identidad cultural.

\begin{tabular}{|c|c|c|c|c|c|c|}
\hline & \multicolumn{5}{|c|}{ COMUNIDAD INMIGRANTE } \\
\hline & & Integración & Asimilación & Segregación & Marginación & Individualismo \\
\hline \multirow{5}{*}{ 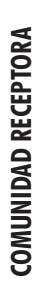 } & Integración & Consenso & Problemático & Conflictivo & Problemático & Problemático \\
\hline & Asimilación & Problemático & Consenso & Conflictivo & Problemático & Problemático \\
\hline & Segregación & Conflictivo & Conflictivo & Conflictivo & Conflictivo & Conflictivo \\
\hline & Exclusión & Conflictivo & Conflictivo & Conflictivo & Conflictivo & Conflictivo \\
\hline & Individualismo & Problemático & Problemático & Problemático & Problemático & Consenso \\
\hline
\end{tabular}

Cuadro 1. Efectos de las estrategias de aculturación

De esta manera, como refleja el Cuadro 1, la interacción entre ambas comunidades puede tener un carácter concordante o consensuado, cuando coinciden las actitudes y estrategias de los dos grupos, o discordante, cuando no coinciden, en cuyo caso se distinguen a su vez situaciones problemáticas y situaciones conflictivas. La coincidencia o no en las estrategias intergrupales determinará la existencia de problemas en diversas áreas sociales y personales, así como el grado en que estos se manifiesten. ${ }^{9}$

\subsection{Teorías de la identidad social y de la autocategorización del yo}

Otra teoría relevante para el estudio de las relaciones de los grupos migrantes es la teoría de la identidad social, formulada por Tajfel (1974, 1978, 1981) dentro de la psicología social, que trata de explicar por qué los individuos suelen favorecer a los miembros del grupo propio (endogrupo) en detrimento de quienes no pertenecen a él (exogrupo). En las formulaciones iniciales, Tajfel $(1974,1978)$ postuló que el comportamiento social de 
un individuo variaba a lo largo de un continuo unidimensional demarcado por dos extremos: el intergrupal, en el cual la conducta estaría determinada por la pertenencia a diferentes grupos o categorías sociales, y el interpersonal, en el que la conducta estaría determinada por las relaciones personales con otros individuos y por las características idiosincráticas. Según esta teoría, una parte de la autoimagen de los individuos en relación con el mundo físico y social que les rodea es aportada precisamente por la pertenencia a ciertos grupos o categorías sociales (Tajfel 1981: 255). Las personas buscan maximizar su autoestima mediante la identificación con todos aquellos grupos sociales específicos a los que pertenecen, intentando además que sean valorados de forma positiva en comparación con los otros grupos. Según Tajfel, los individuos tienen propensión a clasificar a las personas en categorías o grupos sociales y, una vez hecha la clasificación, se acentúan las barreras entre grupos subrayando las igualdades con el grupo propio y las diferencias intergrupales. Además, al sentirse miembros de un grupo aumentan su autoestima y evalúan a los miembros del endogrupo más favorablemente. Cuando los individuos se identifican con un grupo y observan al resto como miembros de otro grupo distinto al propio, a menudo tienden a despersonalizar a los demás, considerándolos como seres que reaccionan de un modo determinado por pertenecer a un determinado grupo y no como individuos con rasgos personales o diferencias respecto al grupo propio. De este modo, se crean estereotipos y prejuicios entre los grupos debido a la división entre endogrupos y exogrupos.

La identidad social sería, pues, «el conocimiento que posee un individuo de que pertenece a determinados grupos sociales junto a la significación emocional y de valor que tiene para él dicha pertenencia» (Tajfel 1981: 255). La identidad constituye, por encima de todo, un dilema entre la singularidad de uno mismo y la semejanza con los otros, entre las peculiaridades de nuestra forma de ser o sentir y la homogeneidad del comportamiento: de esta manera, a veces actuamos como "yo" y otras como "nosotros".

Turner (1982, Tajfel y Turner 1979) complementó las ideas de Tajfel proponiendo un marco conceptual que permitiese explicar cómo un mismo individuo puede mantener conductas muy diversas en función de la interacción entre sus características personales y el contexto social. Su teoría, conocida como la autocategorización del yo, trata de explicar cuál es el proceso que lleva a las personas a incluirse en una categoría u otra, lo cual dependerá de las circunstancias sociales en las que se encuentren.

La teoría de la identidad social propone que los individuos pueden no solo identificarse fuerte o débilmente con el propio grupo, sino también hacerlo de modo positivo o negativo. Desde estos postulados y centrándose específicamente en la contribución de la lengua a la construcción de la identidad, surge la teoría de la identidad etnolingüística (Azurmendi, Bourhis, Ros y García 1998), sintagma que define la representación interna, positiva

Lengua y migración / Language and Migration 12:1 (2020) Monográfico, 39-81

Edición impresa: ISSN 1889-5425. Edición en línea: ISSN 2660-7166. @ Universidad de Alcalá 
o negativa, de sí mismo como miembro del grupo que un individuo se crea a partir de sus circunstancias lingüísticas. La identidad etnolingüística surgiría, por tanto, del proceso de identificación social que generan las relaciones intergrupales entre los grupos etnolingüísticos. Aunque por lo general la valoración de la lengua propia produce una identidad positiva, puede haber casos en los que un individuo genere una identidad social negativa en relación con su propia lengua o variedad lingüística. Los autores ponen como ejemplo lo que sucedió en la época franquista con los sujetos nacidos en territorios bilingües de España: puesto que los individuos no eligen haber nacido de padres de lengua española o de lengua "autonómica", para algunos su origen puede proporcionar una identidad social positiva, mientras que para otros ser miembro de ese grupo puede percibirse como negativo. Estos presupuestos son de fácil aplicación a lo que sucede entre la población migrante y, de manera más clara, entre los hijos de los inmigrantes, teniendo en cuenta especialmente que las teorías identitarias actuales enfatizan la construcción, más que la mera recepción de características (Eckert 2016).

\subsection{Teoría de la acomodación comunicativa}

El proceso de integración sociolingüística no puede entenderse adecuadamente sin conocer cómo se produce el proceso de acomodación comunicativa entre los grupos en contacto (Bourhis y Giles 1977, Giles 1984) y en qué medida tienen lugar los movimientos de convergencia o divergencia, dado que "«interaction is a subtle balance between needs for social inclusiveness on the one hand, and for differentiation on the other» (Giles y Ogay 2007: 294). La acomodación comunicativa incluye aspectos diversos, que van desde la elección del idioma hasta los aspectos paralingüísticos usados en la interacción, pasando por el acento o las variantes dialectales. La convergencia se produce cuando el hablante aproxima sus usos lingüísticos y comunicativos a los de su interlocutor, mientras que con la divergencia el hablante mantiene sus propios usos frente a los de su interlocutor, sin acercarse a ellos, u opta por recursos y elementos que se alejan en frecuencia o forma de los de la comunidad de acogida. Las razones por las que un hablante elige una estrategia u otra pueden ser variadas (Molina Martos 2010: 30; Giles y Ogay 2007: 296-297): la convergencia puede emplearse para mejorar la eficacia comunicativa, obtener la aprobación social o proyectar una imagen personal positiva; la divergencia, en cambio, sirve para mantener la distancia social, preservar la identidad individual o de grupo o proyectar una imagen social determinada.

Las estrategias de acomodación lingüística pueden reinterpretarse como recursos y estrategias de que dispone el hablante para manifestar su propia identidad o, mejor, expresar sus identidades múltiples, en la 
medida en que al aproximarse o alejarse a su interlocutor está mostrando la medida en que desea pertenecer al nuevo grupo.

\subsection{Aportaciones de la lingüística del contacto}

Las bases teóricas que sustentan el análisis de la inmigración deben considerar todas aquellas aportaciones teóricas y metodológicas que han surgido de la sociolingüística y la sociología del lenguaje o que han servido habitualmente como instrumento metodológico, especialmente aquellas que se han dedicado al estudio del contacto de lenguas. En el análisis de los comportamientos lingüísticos de la población migrante se debe atender a los procesos de interdialectalización (Trudgill 1986), cuando se trata de inmigrantes que comparten la misma lengua, o de interlengua (Corder 1967, Selinker 1969, 1972), cuando se trata de la adquisición de la nueva lengua por parte del inmigrante. Entre las nociones útiles para analizar el proceso de integración, habrá que atender a conceptos básicos habituales de la sociolingüística, como pueden ser los de bilingüismo o diglosia (Ferguson 1959, Fishman 1979), los de nivelación, simplificación, hiperdialectalismo y reasignación de variantes (Penny 2004), análisis de errores (Corder 1967, 1971, Fernández 1997), interferencia y transferencia (Weinreich 1953, Selinker 1972), cambio de código, mezcla de lenguas (Gumperz 1982, Poplack y Sankoff 1984), así como fenómenos más específicos como los de préstamo o calco.

\subsection{El modelo piramidal de integración}

Para Moreno Fernández, el proceso de integración puede identificarse mediante una combinación de indicadores sociales y lingüísticos. Define la integración como el "proceso de ajuste mutuo, por parte de una población inmigrante y de una población residente, que permite la construcción intersubjetiva de la realidad social de ambas poblaciones y que las lleva a compartir unos valores, sean los propios de la población residente, sean los de la población residente e inmigrante" (Moreno Fernández 2009: 131). No obstante, la integración social no puede entenderse sin que exista integración sociolingüística. El modelo, que gráficamente se representa en forma de pirámide invertida (Moreno Fernández 2009: 133), es un modelo gradual del proceso de integración, conformado por cuatro niveles asociados a las diversas experiencias vitales de los inmigrantes (Figura 3). ${ }^{10}$ 


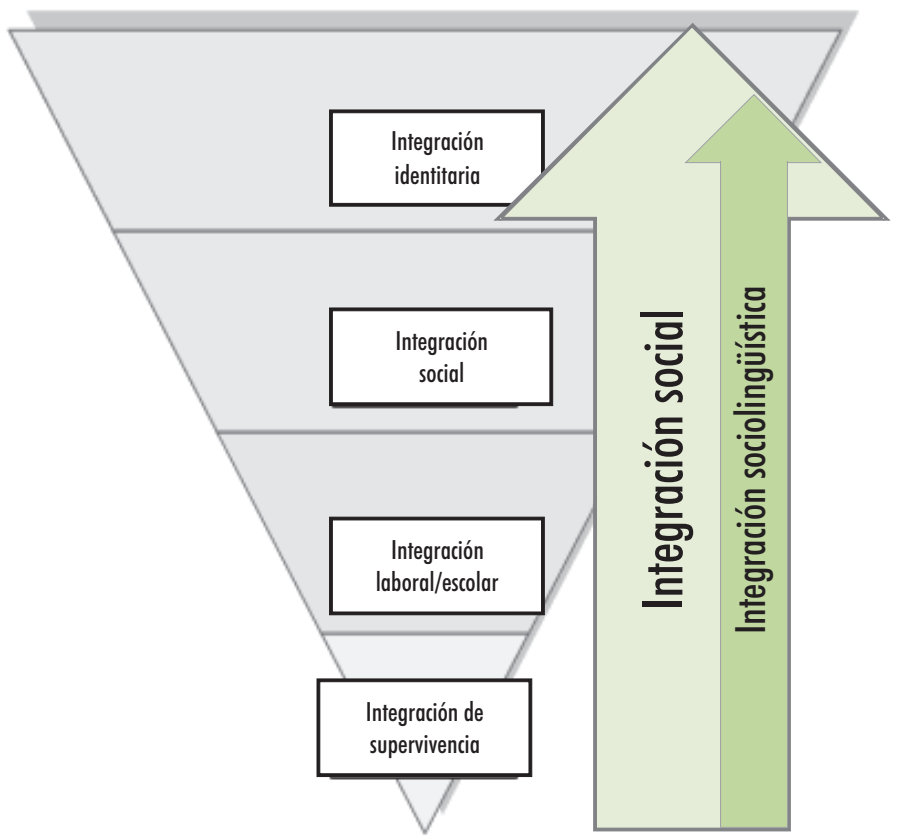

Figura 3. Pirámide del proceso de integración.

(Fuente: reelaboración a partir de Moreno Fernández 2009: 133)

Según se resume en el Cuadro 2, el proceso se inicia en el nivel 0 o integración de supervivencia, en el que la persona migrante trata de cubrir sus necesidades básicas de subsistencia. Desde el punto de vista (socio)lingüístico y comunicativo, esta fase se caracteriza por un limitado dominio de las habilidades lingüísticas y comunicativas, así como por la limitada identificación de las pautas sociales y culturales. El nivel 1, de integración laboral o escolar, suele asociarse a la obtención de un puesto de trabajo (aunque a menudo es precario) y la incorporación al sistema escolar de los hijos del inmigrante. En esta fase, aumenta el dominio lingüístico, incluido el léxico de especialidad; el inmigrante participa en interacciones sociales de carácter laboral y escolar y es capaz de expresar funciones comunicativas básicas como opiniones o gustos; sociolingüísticamente se inicia el proceso de familiarización con los referentes sociales y culturales de la comunidad receptora y el inmigrante toma conciencia de su propio aprendizaje. El nivel 2, denominado de integración social, una vez lograda la integración laboral y escolar, permite al individuo acceder a ciertos ámbitos tradicionalmente reservados a la población residente, así como incorporarse a ámbitos variados de la vida pública y las relaciones interpersonales. En el plano sociolingüístico y comunicativo, la persona migrante adquiere nuevas habilidades lingüísticas y comunicativas que le permiten el acceso a distintos ámbitos públicos y a interrelaciones con otros grupos, es capaz de 
llevar a cabo diversas funciones lingüísticas que le permiten no solo expresar las ideas propias de manera estructurada, sino también influir en el interlocutor; en el plano sociocultural, es capaz de actuar de intermediario cultural. El último nivel es el 3, etiquetado como integración identitaria, se produce cuando el inmigrante es capaz de establecer relaciones sociales complejas en la sociedad de acogida, que se convierte de hecho en "su" comunidad, en la que desarrolla su propia identidad, a veces optando por su identidad de origen y otras por la de la comunidad de llegada. Sociolingüística y comunicativamente, este nivel se adquiere cuando el inmigrante ha alcanzado un nivel de dominio similar al del grupo autóctono, lo que le permite cumplir todas las funciones comunicativas necesarias para el desempeño de su actividad social y personal; supone también el conocimiento y manejo de las actitudes hacia la lengua y la cultura de la comunidad de acogida y la valoración de la cultura propia.

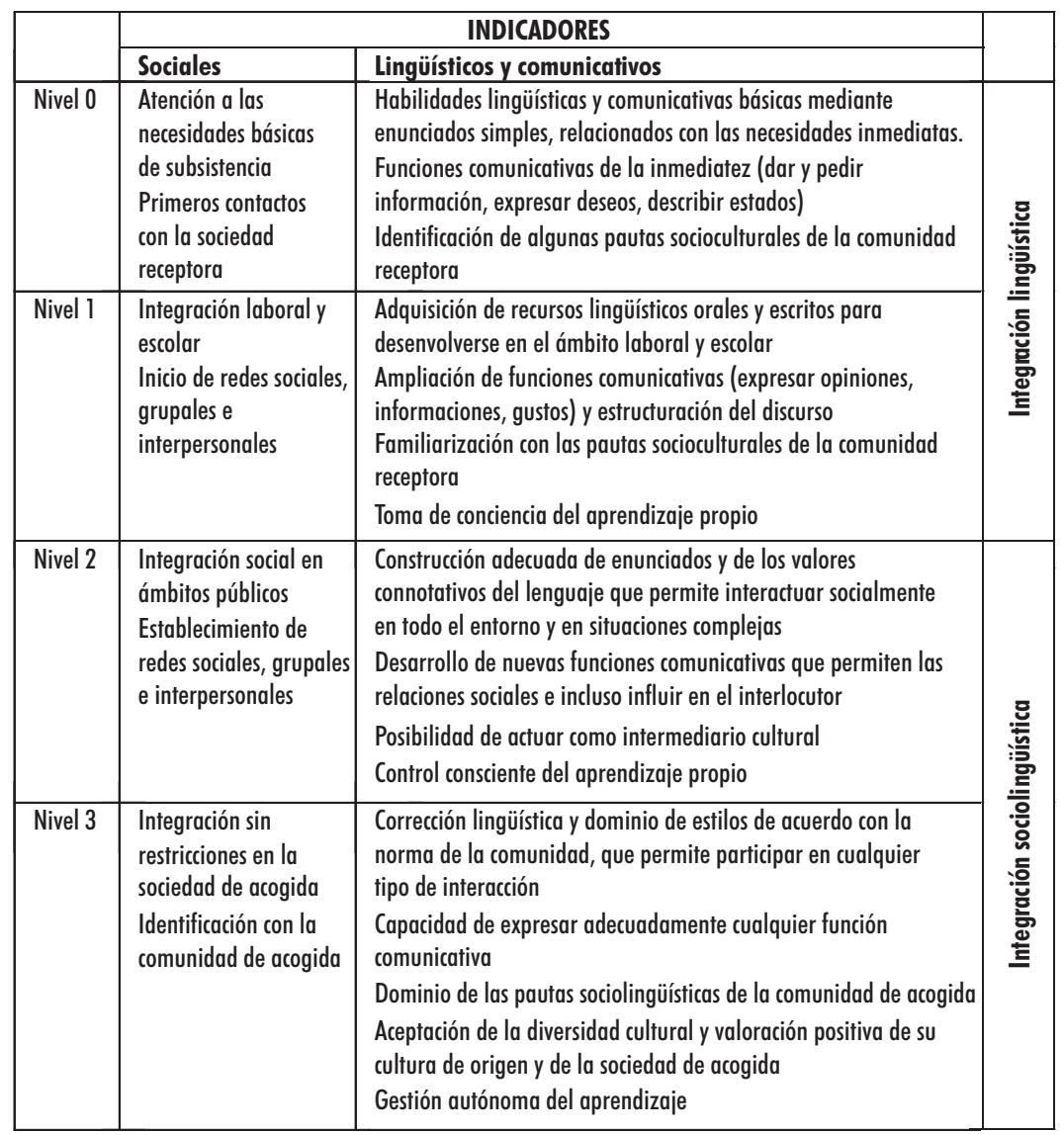

Cuadro 2. Indicadores de integración (elaborado a partir de Moreno Fernández 2009)

Lengua y migración / Language and Migration 12:1 (2020) Monográfico, 39-81 Edición impresa: ISSN 1889-5425. Edición en línea: ISSN 2660-7166. @ Universidad de Alcalá 
En los niveles 0 y 1 se puede hablar tan solo de integración lingüística, que implica únicamente el conocimiento de la lengua residente $-y$ que, por tanto, puede ser un aspecto previo a la llegada del inmigrante o incluso constituir su propia lengua materna-, mientras que la integración sociolingüística se dará solo cuando se alcanzan los niveles 2 y 3 , que exige competencia sociolingüística, es decir, conocimiento de las pautas sociolingüísticas de la comunidad de acogida y habilidad para usarlas de manera adecuada.

\section{Un modelo para el análisis de la integración sociolingüística: dimensiones e instrumentos}

Dada la complejidad que reviste el proceso de integración sociolingüística, cualquier acercamiento que pretenda explicar este fenómeno ha de adoptar una perspectiva multidisciplinar, en la que intervengan teorías, marcos conceptuales y técnicas procedentes al menos de la Sociología, la Psicología Social, la Etnografía de la Comunicación, la Sociología del Lenguaje, la Sociolingüística y la Lingüística (Moreno Fernández 2009). En esta línea, Gugenberger (2007: 21) propone tomar en cuenta las diferentes situaciones en que se produce la migración y los diversos efectos que puede ocasionar el contacto de lenguas, considerando las siguientes áreas de análisis:

1. El marco político, social, cultural y (socio)lingüístico de la sociedad de origen y de la sociedad receptora.

2. Los factores específicos grupales e individuales antes y después de la migración.

3. La instancia intermediaria cognitivo-emotivo-motivacional.

4. Las redes lingüístico-sociales.

5. Las estrategias de aculturación, incluyendo sus implicaciones lingüísticas.

A partir de estos presupuestos, se presenta ahora un modelo que recoge las dimensiones que han de tenerse en cuenta para abordar el análisis de la integración sociolingüística de la población migrante (Figura 4). El modelo toma como ejes centrales la persona migrante, con sus características individuales y psicosociales, y la variedad o variedades que surgen del contacto, esto es, la interlengua en el caso de que se trate de una L2 para el migrante, o el interdialecto si se trata de una variedad diferente dentro de la L1. Para el análisis completo y adecuado del proceso hay 
que tener en cuenta dos dimensiones horizontales: las circunstancias contextuales de la sociedad de partida y las de la sociedad de llegada.

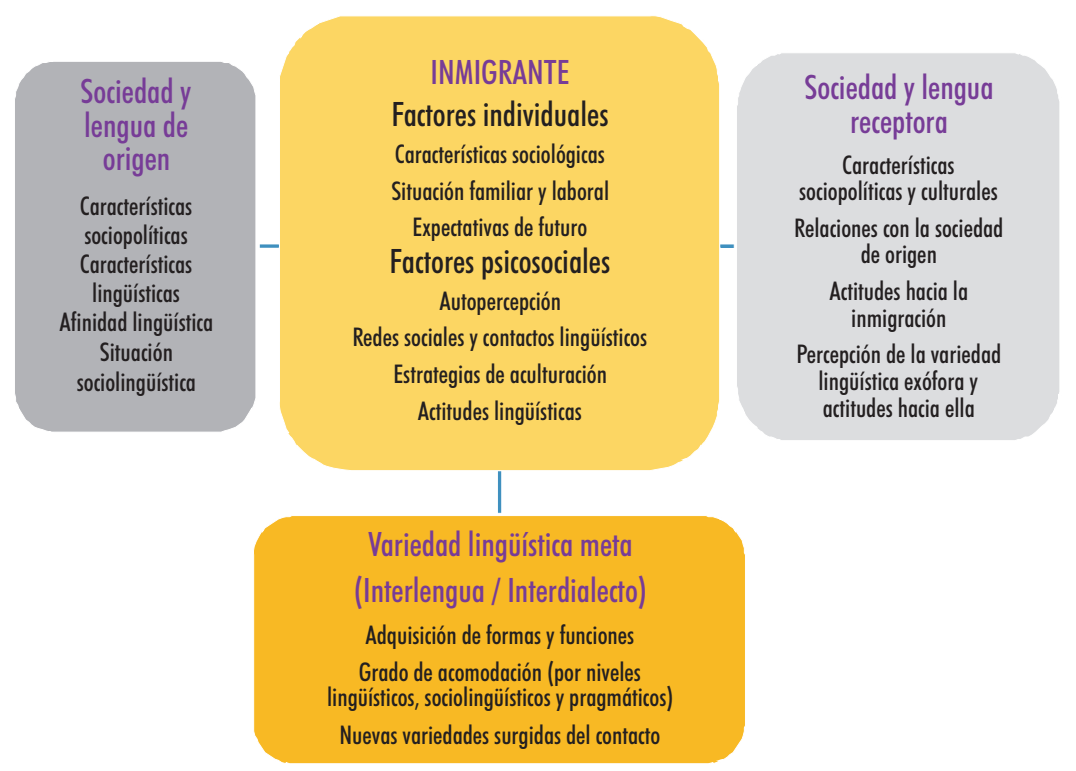

Figura 4. Dimensiones del análisis de la integración sociolingüística

\subsection{Dimensiones}

\subsubsection{La persona migrante}

El modelo que se presenta toma como centro del análisis a la persona migrante y trata de interpretar su realidad a partir de sus características individuales y psicosociales, entre ellas las que lo caracterizan desde el punto de vista sociológico (el sexo, la edad, el grado de formación, etc.) y psicológico (carácter, motivación, etc.). Las circunstancias que rodean la situación familiar y laboral del inmigrante resultan a menudo decisivas para interpretar qué sucede en el proceso vital del sujeto y en el de integración. En el análisis deben tenerse en cuenta no solo las circunstancias objetivas específicas en las que se encuentra el sujeto, sino también atender a la percepción de su situación socio-laboral y la relación con la sociedad receptora, así como de su propia variedad lingüística en el nuevo contexto social (Caravedo 2014).

Una consideración elemental que hay que hacer es que, aunque a menudo la dicotomía se establece entre grupo inmigrante y grupo residente, los inmigrantes no conforman un grupo monolítico, sino que

Lengua y migración / Language and Migration 12:1 (2020) Monográfico, 39-81

Edición impresa: ISSN 1889-5425. Edición en línea: ISSN 2660-7166. @ Universidad de Alcalá 
entre ellos hay muchos subtipos. Una subclasificación evidente es la que se forma en relación con la nacionalidad del migrante, $-\mathrm{y}$ aún aquí hay que tener en cuenta las diferencias internas, a veces diferencias considerables y hasta extremas, como sucede en el caso de los ecuatoguineanos asentados en Madrid (Schlumpf 2020a y 2020b) - o el que se forma según el migrante comparta o no la lengua nativa la población residente.

En relación con la edad de llegada a la sociedad receptora, junto a la tradicional distinción que solo diferenciaba entre migrantes de primera generación, los que han nacido fuera del país de destino, y de segunda generación, los nacidos ya en el país de destino de los padres, Rumbaut (2004), tomando en cuenta el diferente grado de adquisición lingüística y sociolingüística y los problemas de adaptación que pueden tener los sujetos en función de la edad, propone considerar también grupos intermedios dentro de los nacidos fuera del territorio de acogida. De este modo, designa como generación 1.25 a aquellos que llegaron al país de destino cuando tenían entre 13 y 17 años, generación 1.5 a los llegados cuando tenían entre 6 y 12 años, y generación 1.75 a los que tenían entre 0 y 5 años al llegar. ${ }^{11}$

En los estudios recientes sobre migración se suelen distinguir tres modelos de migrantes de acuerdo con su patrón de comportamiento en el proceso migratorio (Gugenberger y Mar-Molinero 2018). El primer modelo, el del migrante clásico, cuyo prototipo es quien sale de su país para asentarse en otro de manera permanente, caracteriza los movimientos migratorios del siglo XIX y la primera mitad del XX, y también en la actualidad en muchos sitios. El segundo modelo, el inmigrante de retorno, es aquel que sale de su país de manera transitoria, con idea de regresar a corto plazo a su lugar de origen. Este tipo de migrante tuvo especial relevancia en Europa a mediados del siglo XX con los llamados "trabajadores invitados". En los últimos años ha surgido un tercer modelo de migrante, el migrante transnacional, que se caracteriza por vivir en más de una localidad y a menudo por saltar las fronteras nacionales para acudir a otros países en busca de otras posibilidades. Este tipo de migrante a menudo utiliza la tecnología que el mundo moderno pone a su alcance para mantener contactos habituales con la sociedad de origen y con otros territorios por donde pasa. De este modo, lo característico de esta población es el desarrollo de identidades múltiples, posibilitadas por la comunicación con esos distintos espacios y grupos. A menudo, sin embargo, en los estudios sobre comunidades de habla concretas resulta complicado encontrar migrantes de cada uno de estos tipos. Esta carencia se puede solventar tomando en consideración las expectativas de futuro de la persona migrante, pues se ha podido comprobar hasta qué punto estas afectan a las actitudes hacia la sociedad y la lengua de la sociedad receptora, entre otros muchos aspectos (Paredes y Sancho 2018). 
En un sentido similar, resulta clave para el análisis del proceso de integración y para conocer las estrategias y actitudes del individuo conocer las redes sociales que establece $-\mathrm{y}$ al respecto no está de más recordar la importancia actual de la comunicación a través internet-. El análisis de las redes ha de tener en cuenta los vínculos que se establecen con la sociedad de origen, el número de vínculos, el tipo y la frecuencia de los contactos y, paralelamente, los que la persona migrante establece en la sociedad receptora. En este último caso, es habitual que las redes sociales estén conformadas por sujetos de diferentes nacionalidades que comparten la situación de migración (Potowski 2016). En el análisis hay que estar atento a las relaciones que se dan entre los grupos que comparten la misma variedad lingüística, para identificar procesos de interdialectalización que pueden surgir al margen de los que se dan respecto a la variedad de acogida.

Aplicando el modelo de aculturación de Berry a la práctica comunicativa de un individuo o un grupo migrante en situaciones de contacto de lenguas diferentes, Gugenberger $(2007,2018)$ identifica cuatro estrategias: integración, asimilación, separación y oxidación (Tabla 3).

\begin{tabular}{|c|c|c|c|}
\cline { 3 - 4 } \multicolumn{2}{c|}{} & \multicolumn{2}{c|}{ LENGUA DE LA SOCIEDAD RECEPTORA } \\
\cline { 2 - 4 } \multicolumn{2}{c|}{} & Mantenimiento & Abandono \\
\hline $\begin{array}{c}\text { LENGUA } \\
\text { DE } \\
\text { ORIGEN }\end{array}$ & Mantenimiento & Integración & Separación \\
\cline { 2 - 4 } & Abandono & Asimilación & Oxidación \\
\hline
\end{tabular}

Tabla 3. Estrategias lingüísticas de aculturación, según Gugenberger

(2007, 2018)

La estrategia de integración implica el mantenimiento de la variedad propia y la adquisición de la lengua de la sociedad receptora, de manera que ambas pasan a formar parte de la identidad del individuo. Son típicas de esta estrategia el cambio de código (code-switching) y la mezcla de códigos (code-mixing) cuando se usan de manera intencionada según los intereses individuales. La estrategia de asimilación se produce cuando se abandona la lengua de origen y se adopta la de la sociedad de acogida, ya sea por una decisión voluntaria, ya por imposibilidad de uso en la nueva situación. La nueva lengua sirve como elemento de identidad. La tercera estrategia es la de separación, que se produce cuando no se adopta la lengua de la sociedad receptora y se conserva la propia a través de los contactos con la sociedad de origen; la identidad se vincula con la lengua materna. La última estrategia, de oscilación, se produce cuando el migrante no se decide por una u otra lengua, sino que emplea 
una u otra en función del interlocutor; suele ser un estadio transitorio. En esta estrategia puede aparecer el code-mixing, pero no de manera intencionada.

Por último, para la sociolingüística en general, el conocimiento de las actitudes lingüísticas es objetivo prioritario, dado el carácter explicativo que tienen sobre el comportamiento y las proyecciones sobre el futuro que posibilitan. El estudio de actitudes, por ello, suele ser objeto de atención preferente en los estudios sobre migración, generalmente usando como herramienta metodológica el cuestionario. Este debe atender a los tres componentes de la actitud, el cognitivo, el afectivo y el conativo (López Morales 1989: 231-242, Moreno Fernández 2005: 180-187) y para ser completo no debe limitarse solo a recoger actitudes de manera descontextualizada, sino presentar objetos concretos, es decir, muestras de variedades lingüísticas sobre las que los encuestados deban pronunciarse.

\subsubsection{La variedad lingüística meta}

El modelo, puesto que se plantea desde la sociolingüística, enfatiza también las dimensiones relativas al lenguaje y la comunicación, destacando de este modo la importancia de la lengua en el proceso migratorio en general (Gutiérrez 2017) y en el de la integración en particular. Como se ha señalado, integración lingüística e integración social corren a la par, por lo que no es posible entender la segunda sin tener en cuenta la primera.

No se puede entender el proceso de integración, por tanto, sin conocer el estado lingüístico y sociolingüístico en el que se encuentra el individuo, para lo cual es imprescindible conseguir muestras de lengua hablada de las personas migrantes en diferentes situaciones de comunicación. Los materiales obtenidos han de posibilitar la descripción realista del comportamiento lingüístico de los grupos de población migrante y su análisis ha de permitir la descripción de la interlengua, en el caso de hablantes cuya lengua materna no es idéntica a la de la sociedad de llegada, o el interdialecto, para los sujetos cuya lengua materna es de una variedad dialectal diferente de la de la sociedad receptora.

Para los procesos de acomodación, es necesario combinar el análisis de los usos reales, obtenidos en las entrevistas, con las actitudes manifestadas, conseguidas a través de los cuestionarios y la propia entrevista, y ponerlos en un eje que contraste, por un lado, con los usos lingüísticos y comunicativos de la población de origen y, por otro, con los de la sociedad de acogida. En este contraste hay que complementar el análisis de qué formas lingüísticas se han adquirido, incluyendo las variantes, así como con las funciones que se les asignan en la sociedad receptora, esto es, el significado social que se les atribuyen a esas formas. La determina- 
ción del nivel de integración sociolingüística vendrá dada por diferencias cuantitativas y cualitativas de inventario o diferencias de función. Ya se ha podido comprobar (Sancho 2014; Molina Martos 2020, Olimpio de Oliveira en prensa, Cestero 2020) que el proceso de acomodación se cumple a diferente ritmo y con distinta intensidad en función de los planos lingüísticos: la acomodación en el nivel léxico, el pragmático (formas de tratamiento, cortesía) o el fraseológico se produce de forma más rápida que otros niveles más "internos", como el gramatical o el fónico. La adopción de estrategias de acomodación diversas, por otra parte, se ofrece como un recurso que posibilita al individuo mostrar sus identidades múltiples adaptadas a las circunstancias comunicativas concretas. ${ }^{12}$

Por último, junto a las nuevas variedades que surgen del contacto entre la lengua de la persona migrante y la de la sociedad de acogida, resulta de gran interés observar qué nuevas variedades surgen como consecuencia de la hibridación cultural y lingüística entre los grupos de inmigrantes.

\subsubsection{La sociedad de origen}

El análisis de la sociedad de origen tiene como objetivos revelar, en primer lugar, las circunstancias sociales o políticas asociadas a los procesos migratorios y, en segundo lugar, en qué medida esas circunstancias afectan al proceso de integración en los aspectos lingüísticos y sociolingüísticos. El análisis de las características lingüísticas de la sociedad de origen incluye el análisis desde la sociología de la lengua $y$, en los casos de bilingüismo, el estatus de cada una de ellas, su prestigio abierto o encubierto, el uso social y las posibles situaciones de diglosia, y otros factores como el grado de estandarización y normalización o las políticas lingüísticas que se llevan a cabo en el país. En este sentido, es posible establecer una escala de complejidad sociolingüística, que describiría escenarios de monolingüismo (con una única variedad o con más de una), bilingüismo o multilingüismo, con las diferentes relaciones entre estas lenguas.

Otro aspecto relevante para el proceso de integración sociolingüística es la distancia entre la lengua de la sociedad de origen y de la sociedad receptora. En este sentido, es posible elaborar, como propone Moreno Fernández (2009: 142) para el caso del español, una "escala de afinidad" de las lenguas y variedades de migración, como la siguiente: 


\begin{tabular}{cccccc}
\hline \multicolumn{1}{c}{1} & & & & & \\
& 2 & 3 & 4 & 5 & 6 \\
\hline Lengua & Lengua & Lengua & Lengua & Variedad de & Variedad de \\
china & semítica & eslava & románica & español & español \\
& (árabe) & & & alóctona & autóctona
\end{tabular}

Tabla 4. Escala de afinidad entre las lenguas de inmigración y la lengua española (Fuente: elaborado a partir de Moreno Fernández 2009)

\subsubsection{La sociedad receptora}

La descripción sociológica de la sociedad receptora es requisito ineludible para sustentar cualquier afirmación que se haga sobre el proceso de integración sociolingüística. Estos datos pueden venir de diversas fuentes: informes y estudios sociológicos, sociodemográficos, descripciones dialectales y sociolingüísticas. El estudio de las percepciones, creencias y actitudes, orientados a identificar las estrategias de aculturación de los grupos y los individuos, puede hacerse mediante las técnicas habituales en Sociología, el cuestionario o la entrevista. La descripción de la situación sociolingüística de la sociedad debe atender al grado de complejidad idiomática de la sociedad a la que accede la persona migrante, que abarca desde el monolingüismo con una sola variedad o con más de una hasta el plurilingüismo con los diversos tipos de relaciones que desarrollan las situaciones de lenguas en contacto.

A las fuentes habituales y básicas de información sociológica se pueden sumar los trabajos que permiten identificar las actitudes subyacentes: por ejemplo, el análisis de los discursos especialmente los de la esfera pública. Es de gran relevancia el tratamiento que reciben los alumnos extranjeros en el sistema educativo y en los contextos de aprendizaje (Martín Rojo, 2003; Fernández López 2019) o la forma en que los medios de comunicación presentan los procesos migratorios y a los inmigrantes. Los trabajos de L. Guerra y M. E. Gómez sobre la representación de la inmigración en los medios de comunicación (Guerra 2011, 2016; Guerra y Gómez 2017) han puesto de relieve la visión deformadora de la población migrante que transmite la prensa escrita, que la presenta a menudo asociada a aspectos negativos. Los autores denuncian prácticas inadecuadas, como la de destacar expresamente la nacionalidad extranjera de los autores de sucesos y noticias negativas (delincuencia, pobreza, violencia), aunque en la propia noticia el origen del autor fuera detalle irrelevante y contraviniendo, por otra parte, las normas éticas y de estilo del propio medio. En el corpus de noticias sobre movimientos migratorios publicadas entre noviembre de 2013 y noviembre de 2015 en diarios españoles e hispanoamericanos (Guerra y Gómez 2017), destacan también el preocu- 
pante aumento de la tendencia a presentar inmigración y terrorismo como temas vinculados en las noticias que afectan a la inmigración. Este tipo de estudios, que muestran de manera indirecta, la percepción de la inmigración y que pueden afectar a las creencias y las actitudes hacia ella, pueden entrar en contradicción con datos obtenidos a través de otras fuentes, como las encuestas o cuestionarios, donde a veces el sujeto tiende a responder de manera "políticamente correcta".

\subsection{Los instrumentos}

Metodológicamente, los instrumentos primarios previstos para abordar el estudio de las dimensiones señaladas en el apartado anterior son la entrevista y el cuestionario. Los modelos que se presentan aquí son los usados en el proyecto INMIGRA-CM de la Comunidad de Madrid.

\subsubsection{La entrevista (relato de vida)}

El método básico de obtener muestras de lengua hablada de los grupos de población migrante es la entrevista. En concreto, la seguida en el proyecto madrileño consiste en una entrevista semidirigida, que se estructura en forma de relato de vida y va orientada a que el entrevistado pueda expresar sus sensaciones y opiniones acerca del proceso migratorio, desde su lugar de origen hasta su situación actual. En esta entrevista se le concede un peso muy importante a la influencia de la lengua en ese periplo vital. ${ }^{13}$ Formalmente se compone de seis módulos (Anexo 1): 1. Llegada a España, 2. El pasado en el país de origen, 3. La llegada a España, 4. Opiniones sobre Madrid, 5. Trabajo, 6. Vida cotidiana en España, 7. Familia e hijos y 8. Expectativas de futuro.

\subsubsection{Los cuestionarios de actitudes}

El cuestionario, adaptación del usado en el proyecto PRECAVES XXI (Cestero y Paredes 2015), es un instrumento complejo, dividido en dos partes, ambas aplicables a la población residente y a la población migrante. La primera parte es un cuestionario, que podríamos denominar "clásico" (véase Anexo 2A), que se divide en tres bloques: el primero recoge información sociológica, incidiendo en las redes sociales que establece la persona; el segundo consta de 32 afirmaciones sobre las cua-

Lengua y migración / Language and Migration 12:1 (2020) Monográfico, 39-81

Edición impresa: ISSN 1889-5425. Edición en línea: ISSN 2660-7166. @ Universidad de Alcalá 
les el encuestado debe indicar su grado de acuerdo o desacuerdo a partir de una escala Likert de cuatro grados que va de «Nada de acuerdo» a «Totalmente de acuerdo». Estos ítems se integran en ocho bloques temáticos que permiten ir conformando una visión sobre los distintos componentes de la actitud (cognoscitivo, afectivo y conativo) y los posibles factores que la generan. Finalmente, el tercer bloque del cuestionario contiene una pregunta en la que se solicita la valoración del habla de Madrid con relación con la de los propios informantes a través de una escala de diferencial semántico de 6 grados.

La segunda parte (véase Anexo 2B), que es también de aplicación bidireccional, para la población alóctona y para la autóctona, consiste en un cuestionario en el que se emplea como recurso metodológico una cinta estímulo. Se trata de una adaptación de la técnica de pares falsos (matched guise), que mide de manera directa e indirecta (a través de la evaluación de la persona que habla) la percepción de diversas variedades lingüísticas y las actitudes hacia ellas. A los inmigrantes se les pide que evalúen cinco variedades del español (castellano, andaluz, canario, andina, caribeña) entre las que se encuentra la variedad madrileña. A los madrileños, por su parte, se les pide que evalúen la pronunciación de cuatro variedades habladas por inmigrantes de otros tantos orígenes (rumano, polaco, brasileño, marroquí) más una lengua no específicamente de inmigrantes (inglés), que servirá de contraste.

Aunque cuestionarios y entrevistas pueden usarse de manera independiente, lo ideal es que a los sujetos entrevistados se les apliquen también los cuestionarios. De esa manera es posible contrastar los usos reales y las actitudes subyacentes con las actitudes manifiestas abiertamente $y$, en consecuencia, identificar también posibles incoherencias.

\subsubsection{Otras fuentes complementarias y de contraste}

Los datos obtenidos mediante el cuestionario y la entrevista, aparte de poder contrastarse entre sí, sirven también para poder comparar los resultados con los obtenidos por medio de otras fuentes. Es evidente que disponer de unas descripciones lingüísticas y dialectales fiables de la sociedad meta ha de servir como punto de referencia para determinar el proceso de acomodación que los individuos o los grupos han alcanzado. Del mismo modo, lo ideal sería disponer de descripciones de las características lingüísticas de la sociedad de origen, lo cual permitirá ver el grado de aculturación, manifestada en el grado de desapego respecto de los usos lingüísticos de origen. ${ }^{14}$ Fuentes de información complementaria son los informes sociológicos, sociodemográficos, etc., especialmente los que se dedican al análisis de la población migrante. 


\section{Conclusiones}

Si la migración es un fenómeno estructural en las sociedades actuales - dada la intensidad que ha adquirido en todo el mundo como consecuencia, entre otras causas, del imparable desarrollo de la globalización-, la sociolingüística de la migración ha de plantearse como objetivos analizar cómo se produce el contacto entre los grupos sociales involucrados, identificar las consecuencias lingüísticas derivadas de ese contacto y, en última instancia, proponer medidas para favorecer la integración. La complejidad de elementos presentes en el proceso de integración requiere una perspectiva multidisciplinar que tome en consideración todas las dimensiones sociales e individuales que intervienen en ese proceso, y especialmente a las estrategias de aculturación seguidas por los grupos sociales y los individuos que protagonizan el contacto. Todo ello ha de hacerse, además, a partir de un importante acopio de datos que permita cuantitativa y cualitativamente determinar el grado de integración de los grupos sociales y los individuos, así como detectar las posibles dificultades que surjan en este proceso.

En el trabajo se ha presentado el modelo de análisis que se emplea en la red de investigación INMIGRA-CM. Se trata de un modelo complejo basado en las teorías sociológicas, psicológicas, comunicativas, lingüísticas y sociolingüísticas, que toma como centro de análisis la persona migrante con sus características individuales y psicosociales, y busca determinar cómo construye su propia identidad en el nuevo contexto, la cual se manifiesta comunicativamente en la variedad (interlengua o interdialecto) que surge en el contacto con los demás. Todo ello, ha de interpretarse tomando en cuenta la sociedad y la lengua de la que procede la persona migrante y las características de la sociedad y la lengua a la que accede.

El modelo, por último, se presenta como un modelo dinámico, no solo porque toma en cuenta las dimensiones que permiten interpretar la realidad de la inmigración, una realidad fluida y en constante cambio, sino también porque permite describir los distintos ritmos a que se produce el proceso de integración según los grupos sociales y los individuos en función de sus características personales y sus estrategias de aculturación.

Florentino Paredes García

Departamento de Filología, Comunicación y Documentación

Universidad de Alcalá

florentino.paredes@uah.es

ORCID: 0000-0002-6803-1036 


\section{Notas}

1 Este artículo forma parte de las actividades de los proyectos de investigación La población migrante de la Comunidad de Madrid: estudio multidisciplinar y herramientas para la integración sociolingüistica (IN.MIGRA2-CM, ref. H2015/HUM3404) y La población migrante en la Comunidad de Madrid: factores lingüísticos, comunicativos, culturales y sociales del proceso de integración y recursos lingüisticos de intervención" (INMIGRA3-CM, ref.: H2019/HUM-5772), financiados por la Comunidad de Madrid y el Fondo Social Europeo, y Estudio complementario de los patrones sociolingüísticos y procesos de integración sociolingüistica en Madrid (ECOPASIS_MAD) (Ref. FFI201568171-C5-4-P), financiado por el Ministerio de Economía y Competitividad.

2 Coinciden las dos inmigraciones en la dirección adoptada. En cualquiera de los dos tipos, los migrantes van del campo a la ciudad, lo que supone un proceso de urbanización y un crecimiento imparable de los núcleos urbanos. En 2017 había en el mundo 36 megaciudades de más de 10 millones de habitantes, cifra que supera las 100 si se consideran los aglomerados urbanos. Las previsiones para 2030 indican que habrá 2000 millones de nuevos habitantes urbanos.

3 Para España los efectos fueron notables, no solo porque de las cinco ciudades que más crecieron en Europa tres fuesen españolas - Móstoles, Hospitalet y Portugalete-, sino sobre todo porque agudizó el proceso de urbanización y desruralización de la España, que se orientó casi en exclusiva hacia Madrid y las áreas costeras, dejando despobladas las dos mesetas. Desde el punto de vista sociolingüístico, las consecuencias de esta migración nacional son bien conocidas: los inmigrantes que llegaban a la ciudad con sus marcas dialectales de origen, por lo general meridional o de zonas de transición, tuvieron que abandonar los rasgos propios e incorporar los de la comunidad de acogida para librarse del estigma de hablantes rurales o bien adaptarse a las condiciones de bilingüismos del territorio al que accedieron. Además de este proceso de desdialectalización, la urbanización supuso también la convergencia con el estándar, en la medida en que fue acompañada de un alto grado de escolarización de la población.

4 Durante el siglo XX, se sucedieron en España éxodos de personas por causas políticas o económicas. Los destinos de los exiliados fueron fundamentalmente países americanos (México, Cuba, Venezuela, Colombia) y europeos (Francia, la URSS), mientras que la emigración económica se dirigió a destinos europeos (Francia, Reino Unido, Alemania, Suiza, Países Bajos). El número de emigrantes por razones económicas alcanzó la cifra de dos millones de personas en la década de los 60 (Santos 2003)

5 Agradezco a las autoras de las fotografías, Marta Retortillo y Julia M. Hiebler, alumnas de la asignatura de Sociolingüística, que me hayan permitido usarlas para este trabajo.

6 Los autores encuentran los siguientes patrones de distribución: monopoly, cuando una lengua domina sobre todo en las calles económicamente más importantes de una ciudad; gueto o telaraña para la situación de aquellas lenguas de tupida presencia pero en las calles adyacentes a las vías principales; variante progresiva o boca de lobo, cuando las lenguas solo aparecen en áreas periféricas o marginales, con una clara acotación territorial; moteado, si se esparcen por la ciudad, pero de manera no continua; y paisaje lingüístico silencioso o silenciado, que se produce cuando la lengua de un grupo de migrantes no aparece en el paisaje lingüístico urbano.

7 No han faltado otras propuestas, como la de Moreno Fernández (2009: 151), quien prefiere la denominación de Xenolingüística.

8 Un punto importante en este sentido podría ser establecer si en los contextos de contactos de grupos sociales y variedades lingüísticas hay en realidad una sola comunidad de habla en juego y, en todo caso, cómo se va configurando esta.

9 El modelo de Bourhis tenía en cuenta, además, elementos como el origen etnocultural de los grupos de inmigrantes o las circunstancias políticas, demográficas o socioeconómicas del país de acogida. Por otra parte, Navas et al. (2004) han señalado que no siem- 
pre hay coincidencia entre las actitudes y estrategias de aculturización que idealmente sigue cada grupo y las que realmente lleva a cabo y, además, que estas actitudes y estrategias pueden variar en función de los ámbitos de la realidad sociocultural.

10 Lógicamente, el proceso se desarrolla de forma diferente según el hablante sea heteroglósico u homoglósico en relación con la lengua de la sociedad receptora, teniendo en cuenta además que la integración sociolingüística de los hablantes heteroglósicos conlleva también el proceso de adquisición de una segunda lengua.

11 Estas subdivisiones se han empleado también en trabajos de sociolingüística hispana, por ejemplo, en los trabajos de Carmen Silva Corvalán para el español de Los Ángeles (cf. Silva-Corvalán y Enrique Arias 2017: 338-361).

12 En el análisis de la acomodación lingüística hay que atender también a los efectos que las circunstancias de la entrevista pueden ejercer sobre el discurso, y en particular habrá que observar en qué medida interfiere la figura del entrevistador (von Essen 2016).

${ }^{13}$ El conjunto de entrevistas conforma un corpus de grupos de población migrante, que se ha denominado Corpus Dinámico del Español de la Inmigración, CORDIESIN. El corpus, que tiene un carácter abierto, está actualmente compuesto por lenguas de distinta relación tipológica respecto a la lengua española: hispanos (ecuatorianos, dominicanos, colombianos, peruanos, guineoecuatorianos y venezolanos), de lenguas románicas (brasileños y rumanos), de lenguas eslavas (polacos), de lenguas semíticas (marroquíes) y de lenguas orientales (chinos). Los criterios de preestratificación son el sexo, el tiempo de permanencia en España y la localidad de residencia.

14 En el proyecto INMIGRA-CM de la Comunidad de Madrid, los datos de cuestionarios y entrevistas se pueden contrastar con los de otros corpus, como los del PRESEEA de Alcalá (Moreno, Cestero, Molina y Paredes 2002, 2005, 2007) y de Madrid, en el distrito de Salamanca (Cestero, Molina y Paredes 2012, Molina, Paredes y Cestero 2014, Paredes, Cestero y Molina 2015), y en el distrito de Vallecas (Cestero, Molina y Paredes 2020, Molina, Paredes y cestero 2020, Paredes, Cestero y Molina 2020). En cuanto a las actitudes hacia otras variedades del español, se dispone de las informaciones obtenidas a través de los cuestionarios del proyecto PRECAVES XXI (Cestero y Paredes 2018a, 2018b; Paredes y Cestero 2018). Para el léxico, se cuenta con el corpus de Disponibilidad Léxica (Paredes, Guerra y Gómez, en prensa).

\section{Referencias bibliográficas}

Arango, Joaquín. 2013. “Exceptional in Europe? Spain’s Experience with Immigration and Integration”. Washington, D.C.: Migration Policy Institute. Disponible en $<$ http://www.migrationpolicy.org/research/exceptional-europe-spains-experienceimmigration-and-integration $>$ [Consultado el 04/03/2019].

Azurmendi, María José, Richard Y. Bourhis, María Ros e Iñaki García. 1998. “Identidad etnolingüística y construcción de ciudadanía en las Comunidades Autónomas Bilingües (CAB) de España”. Revista de Psicología Social, 13:3. 559-589.

Berry, John W. 1997. "Inmigration, acculturation and adaptation”. Applied psychology: An international review. 46:1. 5-34.

Berry, John W. 2001. “A psychology of immigration”. Journal of Social Issues, 57: 3. 615-631.

Berry, John W. 2005. “Acculturation. Living successfully in two cultures”. International Journal of Intercultural Relations, 29. 697-712.

Bourhis, Richard y Howard Giles. 1977. "The language of intergroup distinctiveness”. En Language, Ethnicity and Intergroup Relations, Howard Giles (ed.), 119-135. Londres: Academic Press.

Bourhis, Richard Y., Lena Celine Moïse, Stephane Perreault y Sacha Senecal. 1997. "Towards an interactive Acculturation Model: A Social Psychology Approach". International Journal of Psychology, 32:6. 369-386.

Lengua y migración / Language and Migration 12:1 (2020) Monográfico, 39-81

Edición impresa: ISSN 1889-5425. Edición en línea: ISSN 2660-7166. @ Universidad de Alcalá 
Caravedo, Rocío. 2014. Percepción y variación lingüística. Enfoque sociocognitivo. Madrid / Frankfurt: Iberoamericana / Vervuert.

Castillo Lluch, Mónica y Daniel Sáez Rivera. 2011. “Introducción al paisaje lingüístico de Madrid", Lengua y migración, 3:1. 73-88.

Castillo Lluch, Mónica y Daniel Sáez Rivera. 2012. «Les empreintes plurilingues et pluridialectales dans le Paysage Linguistique de Madrid». Recherches, 6. 23-52.

Cea D’Ancona, Ma Ángeles y Miguel S. Valles Martínez. 2015. Evolución del racismo, la xenofobia y otras formas conexas de intolerancia en España. Informe-Encuesta 2014. Madrid: Subdirección General de Información Administrativa y Publicaciones. Disponible en http://www.empleo.gob.es/oberaxe/ficheros/documentos/Evolucion Racismo-XenofobiaOtrasFormasConexasIntoleranciaEspana-informe-encuesta2014.pdf. [Consultado el 20/03/2019].

Cestero (2020 en prensa): “Apéndices interrogativos de control de contacto en el habla de inmigrantes colombianos en Madrid: hacia la convergencia con la comunidad de acogida”, Sociolinguistic Studies.

Cestero, Ana Ma , Isabel Molina y Florentino Paredes. 2012. La lengua hablada en Madrid (distrito de Salamanca). Vol.I Hablantes de Instrucción Superior. Alcalá de Henares: Servicio de Publicaciones de la Universidad de Alcalá.

Cestero, Ana M., Isabel Molina y Florentino Paredes. 2020. La lengua hablada en Madrid. Corpus PRESEEA-MADRID I (distrito de Vallecas): Hablantes de instrucción superior, Alcalá de Henares, Servicio de Publicaciones de la Universidad de Alcalá.

Cestero Mancera, Ana M. y Florentino Paredes García (2015). “Creencias y actitudes hacia las variedades normativas del español actual: primeros resultados del Proyecto PRECAVES-XXI”. Spanish in Context, 12/2. 255 - 279. DOI: 10.1075/sic.12.204ces

Cestero Mancera, Ana M. y Paredes García, Florentino. 2018a. "Creencias y actitudes hacia las variedades cultas del español actual: el proyecto PRECAVES XXI”. Boletín de Filología, 53:2. 11-43. Disponible en https://boletinfilologia.uchile.cl/index.php/ $\mathrm{BDF} /$ article/view/51940 [Consultado el 18/10/2019].

Cestero Mancera, Ana M. ${ }^{a}$ y Paredes García, Florentino. 2018b. “Creencias y actitudes de los jóvenes universitarios del centro-norte de España hacia las variedades cultas del español”. Boletín de Filología, 53:2. 45-86. Disponible en https://boletinfilologia. uchile.cl/index.php/BDF/article/view/51941 [Consultado el 18/10/2019].

Colectivo Ioé. 2010. "Discursos de la población migrante en torno a su instalación en España. Exploración cualitativa”. Opiniones y Actitudes, 64. Madrid: Centro de Investigaciones Sociológicas.

https://onlinelibrary.wiley.com/doi/epdf/10.1080/002075997400629

Corder, S. Pit. 1967. "The significance of learners' errors". International Review of Applied Linguistics, 5. 161-170. [Recogido en Corder, S. P. 1981. Error Analysis and Interlanguage. Oxford: Oxford University Press].

Corder, S. Pit. 1971. "Idyosincratic dialects and error analysis". International Review of Applied Linguistics, 9. 149-159.

Eckert, Penelope. 2016. "Variation, meaning and social change". En Sociolinguistics: Theoretical debates, Nikolas Coupland,(ed.), 68-85. Cambridge University Press.

Ferguson, Charles. 1959. “Diglossia”. Word, 15. 325-340.

Fernández, Sonsoles. 1997. Interlengua y análisis de errores: en el aprendizaje del español como lengua extranjera. Madrid: Edelsa.

Fernández López, María del Carmen. 2019. "The Linguistic and Cultural Atlas of Immigration: Multidisciplinary Research for Spanish Classrooms”. Open linguistics. 5:1, 553-569.

Fishman, Joshua A. 1979. The Sociology of Language: An interdisciplinary social science approach to language in society. Rowley, Massachusetts: Newbury House Publisher.

García Vázquez, María Rita. 2008. “Actitudes de aculturación ante la inmigración; opiniones de agentes en el municipio de Vícar (Almería)”. Nimbus 21-22. 121-132.

Lengua y migración / Language and Migration 12:1 (2020) Monográfico, 39-81 Edición impresa: ISSN 1889-5425. Edición en línea: ISSN 2660-7166. C U Universidad de Alcalá 
Giles, Howard (ed.). 1984. The Dinamics of Speech Accomodation. International Journal of the Sociology of Language, 46.

Giles, Howard y Tania Ogay. 2007. Communication Accommodation Theory”. En Explaining communication: Contemporary theories and exemplars, B.B. Whaley y W. Samters (eds.), 293-310. Mahwah, New Jersey: Lawrence Erlbaum.

Godenau, Dirk, Sebastian Rinken, Antidio Martínez de Lizarrondo y Gorka Moreno Márquez (coords.). 2014. La integración de los inmigrantes en España: una propuesta de medición a escala regional. Madrid: Observatorio Permanente de la Inmigración (OPI), Ministerio de Empleo y Seguridad Social. Disponible en http://extranjeros. empleo.gob.es/es/ObservatorioPermanenteInmigracion/Publicaciones/fichas/archivos/OPI_30.pdp. [Consultado el 20/03/2019].

Godenau, Dirk, Rinken, Sebastian, Martínez de Lizarrondo, Antidio, Moreno Márquez, Gorka (coords.) 2017. La integración de los inmigrantes en España: fases, patrones y dinámicas regionales durante el periodo 2007-2015. Madrid: Observatorio Permanente de la Inmigración (OPI), Ministerio de Empleo y Seguridad Social. Disponible en http://extranjeros.empleo.gob.es/es/ObservatorioPermanenteInmigracion/Publicacion es/fichas/archivos/OPI_31.pdf . [Consultado el 20/03/2019].

Guerra, Luis. 2011. "El discurso periodístico sobre la inmigración latinoamericana en España: el corpus de noticias INMIGRA”. Lengua y migración, 3:1. 33-51.

Guerra, Luis. 2016. “La representación de los movimientos migratorios en la prensa de los países hispanohablantes (2013-2015)”. Cuadernos AISPI, 8. 95-118.

Guerra Salas, Luis, y Gómez Sánchez, M. Elena. 2017. “La cobertura de las migraciones en la prensa de los países hispanohablantes (2016)". Revista Nebrija de Lingüistica Aplicada a la Enseñanza de Lenguas, 11:23. 12-28. https://doi.org/10.26378/rnlael112328

Gugenberger, Eva. 2007. “Aculturación e hibrididad lingüísticas en la migración: Propuesta de un modelo teórico-analítico para la lingüística de la migración”. Revista Internacional de Lingüistica Iberoamericana, 5, 2:10. 21-45.

Gugenberger, Eva. 2018. "De inmigrantes a transmigrantes: modelos de migración y sus consecuencias lingüísticas”. En Carolin Patzelt, Carolina Spiegel y Karin Mutz (eds.), Migración y contacto de lenguas en la Romania del siglo XXI / Migration et contact de langues au XXIe siècle, 41-66. Berlin, Bern, Bruxelles, New York, Oxford, Warzawa, Wien: Peter Lang.

Gugenberger, Eva y Clare Mar-Molinero. 2018. “Introducción. El impacto lingüístico de la migración transnacional y la migración de retorno en, desde y hacia el espacio iberorrománico”. Revista Internacional de Lingüística Iberorrománica, 31:1. 7-12.

Gumperz, John J. 1982. Discourse strategies. Cambridge: Cambridge University Press.

Gutiérrez, Rodolfo. 2007. Lengua, migraciones y mercado de trabajo. Madrid: Fundación Telefónica / Instituto Complutense de Estudios Internacionales.

Instituto Nacional de Estadística. 2014. "Notas de prensa. 30 de junio de 2014. Cifras de Población 1-1-2015 y Estadística Migraciones 2014 (provisionales) (2/17)”. Disponible en http://www.ine.es/prensa/np917.pdf. [Consultado el 22/03/2019]

López Morales, Humberto. 1989. Sociolingüística. Madrid: Gredos.

Martín Rojo, Luisa. (dir.). 2003. ¿Asimilar o integrar? Dilemas ante el multilingüismo en las aulas. C.I.D.E.: Ministerio de Educación, Cultura y Deporte.

McAuliffe, Marie y Martin Ruhs (eds.) 2018. Informe sobre las migraciones en el mundo 2018. Ginebra: Organización Internacional para las Migraciones OIM. Disponible en https://publications.iom.int/system/files/pdf/wmr_2018_sp.pdf. [Consultado el 2/4/2019]

Molina Martos, Isabel. 2010. "Procesos de acomodación lingüística de la inmigración latinoamericana en Madrid”. Lengua y migración 2:2. 27-48.

Molina Martos, Isabel. 2020. “Inmigrantes colombianos en Madrid: actitudes lingüísticas y pautas de integración social”. Lengua y migración (en este volumen).

Molina, Isabel, Florentino Paredes y Ana Ma Cestero. 2014. La lengua hablada en Madrid (distrito de Salamanca). Vol. II Hablantes de Instrucción Media. Alcalá de Henares: Servicio de Publicaciones de la Universidad de Alcalá.

Lengua y migración / Language and Migration 12:1 (2020) Monográfico, 39-81

Edición impresa: ISSN 1889-5425. Edición en línea: ISSN 2660-7166. @ Universidad de Alcalá 


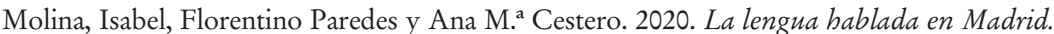
Corpus PRESEEA-MADRID II (distrito de Vallecas): Hablantes de instrucción superior, Alcalá de Henares, Servicio de Publicaciones de la Universidad de Alcalá.

Moreno Fernández, Francisco. 2005. Principios de sociolingüística y sociología del lenguaje, $2^{\mathrm{a}}$. ed. Barcelona: Ariel.

Moreno Fernández, Francisco. 2009. "Integración sociolingüística en contextos de inmigración: marco epistemológico para su estudio en España”. Lengua y migración 1:1. 121-156.

Moreno, Francisco, Ana $\mathrm{M}^{\mathrm{a}}$ Cestero, Isabel Molina y Florentino Paredes. 2002. La lengua hablada en Alcalá de Henares. Corpus PRESEEA-Alcalá. I Hablantes de Instrucción Superior. (CDRom), Vol I. Alcalá de Henares: Servicio de Publicaciones de la Universidad de Alcalá.

Moreno, Francisco, Ana Ma Cestero, Isabel Molina y Florentino Paredes. 2005. La lengua hablada en Alcalá de Henares. Corpus PRESEEA-Alcalá. II Hablantes de Instrucción Media. (CDRom), vol. II. Alcalá de Henares: Servicio de Publicaciones de la Universidad de Alcalá.

Moreno, Francisco, Ana $\mathrm{M}^{\mathrm{a}}$ Cestero, Isabel Molina y Florentino Paredes. 2007. La lengua bablada en Alcalá de Henares. Corpus PRESEEA-Alcalá. III Hablantes de Instrucción Primaria. (CDRom), Vol III. Alcalá de Henares: Servicio de Publicaciones de la Universidad de Alcalá.

Navas, Marisol, Pablo Pumares, Juan Sánchez, M. Carmen García, Antonio Rojas, Isabel Cuadrado, Matilde Asensio y Juan Sebastián Fernández. 2004. Estrategias de aculturación: la perspectiva de los inmigrantes y de los autóctonos en Almería. Almería: Junta de Andalucía.

Olímpio de Oliveira Silva, Maria Eugênia. En prensa. “The Phraseology of Immigrants: A Descriptive Study”. Languages.

Paredes García, Florentino. 2019. “España, rompeolas de los hispanos”, Archi-letras científica (Lingüistica) (monográfico "El español, lengua de migración”, editado por Francisco Moreno Fernández), II. 251-274.

Paredes García, Florentino y Ana M. Cestero Mancera. 2018. “Percepción de las variedades cultas del español por parte de hablantes del centro norte de España según los datos del Proyecto PRECAVES-XXI: el español ejemplar y la variedad propia”. Oralia, 21:1. 87-112.

Paredes García, Florentino y María Sancho Pascual. 2018. “Influencia de las expectativas de permanencia o retorno en la integración sociolingüística de la población migrante en la Comunidad de Madrid”, Revista Internacional de Lingüística Iberoamericana. Vol. "El impacto lingüístico de la migración de retorno y la migración transnacional en, desde y hacia el espacio iberorrománico”, Eva Gugenberger y Clare MarMolinero, (eds.), 16:1-31. 41-67.

Paredes García, Florentino e Isabel Molina Martos. 2019. "La configuración de la norma madrileña desde la dialectología y la sociolingüística”. La configuración histórica de las normas del castellano, Bustos Gibert, Eugenio (ed.), 51-77. Valencia: Tirant Lo Blanch.

Paredes, Florentino, Ana M ${ }^{a}$ Cestero e Isabel Molina. 2015. La lengua hablada en Madrid (distrito de Salamanca). Vol. III Hablantes de Instrucción Primaria. Alcalá de Henares: Servicio de Publicaciones de la Universidad de Alcalá.

Paredes, Florentino, Ana Ma Cestero e Isabel Molina. 2020. La lengua hablada en Madrid. Corpus PRESEEA-MADRID III (distrito de Vallecas): Hablantes de instrucción superior. Alcalá de Henares, Servicio de Publicaciones de la Universidad de Alcalá.

Paredes García, Florentino, Luis Guerra Salas y Elena Gómez. En prensa. Léxico disponible de los estudiantes preuniversitarios de la Comunidad de Madrid. Alcalá de Henares: Servicio de Publicaciones de la Universidad de Alcalá. ISBN:

Poplack, Shana y David Sankoff. 1984. "Borrowing: the synchrony of integration". Linguistics 22:269. 99-136.

Potowski, Kim. 2016. IntraLatino Language and Identity. MexiRican Spanish. Amsterdam: John Benjamins.

Lengua y migración / Language and Migration 12:1 (2020) Monográfico, 39-81 Edición impresa: ISSN 1889-5425. Edición en línea: ISSN 2660-7166. C U Universidad de Alcalá 
Portes, Alejando, Rosa Aparicio y William Haller. 2018. "Hacerse adulto en España: la integración de los hijos de inmigrantes”. Anuario CIDOB de la Inmigración, 2018. 148-181. DOI: doi.org/10.24241/AnuarioCIDOBInmi.2018.148.

Retortillo Osuna, Álvaro. 2009. “Evolución de los modelos psicológicos de aculturación en Norteamérica y en Europa: de la unidimensionalidad a la bidimensionalidad en el tratamiento de la inmigración". Revista de Historia de la Psicología, 30:1. 73-86. Disponible en https://dialnet.unirioja.es/descarga/articulo/2940748.pdf

Rinken, Sebastian. 2015. “Actitudes hacia la inmigración y los inmigrantes: ¿en qué es España excepcional?”. Migraciones, 37. 53-74. Disponible en http://revistas.upcomillas.es/index. $\mathrm{php/revistamigraciones/article/view/5508/5317} \mathrm{[Consultado} \mathrm{el} \mathrm{01/04/2019].}$

Rumbaut, Rubén G. 2004. "Ages, life stages, and generational cohorts: decomposing the immigrant first and second generations in the United States". The International Migration Review, 38:3. 1160-1205.

Sancho Pascual, María. 2014. Integración sociolingüística de los inmigrantes ecuatorianos en Madrid. Alcalá de Henares: Servicio de Publicaciones de la universidad de Alcalá.

Santos, Félix. 2003. Exiliados y emigrados: 1939-1999. Alicante: Biblioteca Virtual Miguel de Cervantes. Disponible en http://www.cervantesvirtual.com/nd/ark:/59851/ bmcbc3v4. [Consultado el 20/11/2019].

Saiz de Lobado, Ester. 2016. “Cartografía del paisaje lingüístico de Lavapiés”. Infografía disponible en http://relacionesinternacionales.media/informes/cartografialinguisti calavapies. [Consultado el 15/09/2019].

Scandroglio, Bárbara, Jorge, S. López Martínez y Ma Carmen San José Sebastián. 2008. “La Teoría de la Identidad Social: una síntesis crítica de sus fundamentos, evidencias y controversias". Psicothema, 20:1. 80-89. Disponible en http://www.psicothema.es/pdf/3432.pdf.

Schlumpf, Sandra. 2020a. "African languages and Spanish among Equatoguineans in Madrid”. Spanish in Context, 17:1. 108-130.

Schlumpf, Sandra. 2020b. "El español hablado por los bubis y los fang de Guinea Ecuatorial. Valoraciones desde la comunidad guineoecuatoriana en Madrid”. Lengua y migración (en este volumen).

Selinker, Larry. 1969. “Language Transfer”, General Linguistics, 9. 67-92.

Selinker, Larry. 1972. "Interlanguage”. International Review of Applied Linguistics in Language Teaching, 10:3. 209-231.

Silva-Corvalán, Carmen y Andrés Enrique-Arias. 2017. Sociolingüística y pragmática del Español. $2^{\mathrm{a}}$ ed. Washington: Georgetown University Press.

Tajfel, Henry. 1974. "Social identity and intergroup behavior". Social Science Information, 13. 65-93.

Tajfel, Henry (ed.). 1978. Differentiation between social groups: Studies in the social psychology of intergroup relations. Londres: Academic Press.

Tajfel, Henry. 1981. Human groups and social categories. Cambridge: Cambridge University Press [Versión en español: Tajfel, Henry. 1984. Grupos humanos y categorías Sociales. Barcelona: Herder].

Tajfel, Henry y John C. Turner. 1979. “An integrative theory of intergroup conflict”. En W.G. Austin y S. Worchel (eds.). The Social Psychology of intergroup relations, 33-47. Monterey, CA: Brooks- Cole.

Trudgill, Peter. 1986. Dialects in Contact. Oxford: Blackwell.

Turner, John C. 1982. “Towards a cognitive redefinition of the social group”. En H. Tajfel (ed.), Social identity an intergroup relations, 33-47. Cambridge: Cambridge University Press.

Weinreich, Uriel. 1953. Languages in Contact: Findings and Problems. New York: Linguistic Circle of New York.

von Essen, María Clara. 2016. "Variedades del español en contacto: acomodación sociolingüística de una comunidad de inmigrantes argentinos en la ciudad de Málaga. Análisis acústico de las variantes alofónicas de / j/”. Lengua y migración, 8:2. 7-43.

Zimmerman, Klaus y Laura Morgenthaler García. 2007. "Introducción: ¿Lingüística y migración o lingüística de la migración?: De la construcción de un objeto científico hacia una nueva disciplina”. Revista Internacional de Lingüistica Iberoamericana, 2:10. 7-19.

Lengua y migración / Language and Migration 12:1 (2020) Monográfico, 39-81

Edición impresa: ISSN 1889-5425. Edición en línea: ISSN 2660-7166. (C) Universidad de Alcalá 


\section{ANEXO 1 \\ ENTREVISTA SEMIDIRIGIDA}

\section{Llegada a España}

- ¿Cuándo llegó a España/Madrid?

- ¿Estuvo en algún otro lugar antes?

- ¿Cómo fue el viaje? ¿Cómo llegó?, ¿en qué medio de transporte viajaba?

- ¿Vino con su familia? ¿Qué supuso / supone para usted que su familia no esté aquí?

\section{El pasado en su país}

- Hábleme un poco de su país. ¿Cómo es? ¿Qué recuerdos tiene de su país? ¿Qué diferencias hay entre las distintas zonas del país? $¿$ Existen distintas maneras de hablar en las distintas zonas del país? ¿En qué lo nota? ¿Qué forma de hablar le gusta más? ¿Quién considera que habla mejor? ¿Distingue a un ecuatoriano por su forma de hablar? Y aquí en Madrid, ¿'les distingue también por su forma de hablar? ¿Percibe por su forma de hablar si llevan más o menos tiempo en España?

- ¿Cómo era su vida en su país?

- ¿Qué recuerdos tiene de cuando era pequeño?

- ¿Cómo era su familia? ¿Cómo era la relación con sus padres? ¿Y con sus hermanos? ¿Y con sus vecinos?

- Cuénteme cómo era cuando iba a la escuela. ¿Cómo era la escuela?

- ¿Tenía muchos amigos? ¿Cómo eran sus amigos? ¿Cómo era la relación con sus amigos?

- ¿Cómo fue su adolescencia?

- ¿Cuándo comenzó a trabajar? ¿Dónde trabajaba? ¿Cómo era su trabajo allí? ¿Le gustaba?

- ¿A qué edad se casó? ¿Cómo conoció a su mujer/marido? ¿Cómo fue su boda? ¿Fue en Ecuador o en España? ¿Son muy diferentes las bodas aquí y allí?

- ¿Tiene hijos? ¿Con qué edad los tuvo? ¿Dónde nacieron?

- ¿Cuándo decidió venir a España? ¿Cómo era su situación allí? ¿Por qué decidió venir solo / con su familia?

- ¿Por qué decidió salir de su país? ¿Por qué eligió España? ¿Por qué Madrid? 


\section{La llegada a España}

- ¿Cómo se sintió al llegar?

- ¿Qué le parece España?

- ¿Cómo se la imaginaba?

- ¿Qué le sorprendió de España? ¿Qué es lo que no le gustó/gusta?

- ¿Conoce otros lugares de España? ¿Ha viajado por otros lugares? ¿Cuál le ha gustado más?

- ¿Por qué ha ido allí? ¿Por trabajo, por turismo? ¿Cuánto tiempo ha estado allí? ¿Cómo era su vida allí? ¿Le gustaba más su vida allí o su vida en Madrid?

- ¿Cómo ha sido su trato con la gente de esos lugares? ¿Percibe diferencias entre la gente de Madrid y la gente de esos lugares? ¿Qué diferencias?

- ¿Le gustaría vivir en otro sitio de España que no sea Madrid?

- ¿Percibe diferencias en el español que se habla en distintas zonas de España? ¿Hay alguna que le guste más?

- ¿Se parece alguna de las maneras en que se habla en Ecuador a alguna de las maneras en que se habla en España? ¿Cuál? ¿En qué aspectos?

- ¿Es muy diferente la vida de Madrid a la de su país? ¿Qué es lo que más le llamó la atención cuando llegó? ¿Qué le gusta de Madrid?

- ¿Qué cosas le parecen características de los madrileños? ¿Y de su manera de hablar? ¿Qué cosas de las que dicen los madrileños le llamaron más la atención cuando llegó? ¿Qué opinión tiene sobre esos fenómenos? ¿Ahora usted emplea esas expresiones, palabras? ¿Sabe cómo se utilizan, en qué contextos? ¿Ha tenido alguna dificultad con esas expresiones?

- En general ¿qué opina de los madrileños? ¿Le gustan? ¿Ha cambiado su opinión sobre ellos a lo largo de su estancia en Madrid? ¿Qué opinaba de ellos al llegar? ¿Y ahora? ¿Qué opina de su manera de hablar? ¿Qué opinaba cuando llegó? ¿Y ahora? ¿Le gusta? ¿Por qué?

\section{Opiniones sobre Madrid.}

- ¿Se sintió bien con los madrileños al llegar?

- ¿Le ha costado integrarse en Madrid?

- ¿Le resulta fácil el trato con los madrileños? ¿Cree que ellos tienen una predisposición positiva hacia la integración de los inmigrantes?

- ¿Cómo ha sido su adaptación en Madrid?

Lengua y migración / Language and Migration 12:1 (2020) Monográfico, 39-81

Edición impresa: ISSN 1889-5425. Edición en línea: ISSN 2660-7166. (C) Universidad de Alcalá 
- ¿Los madrileños le ayudaron al llegar? ¿Y ahora?

- ¿Se siente cómodo cuando está con personas de Madrid? ¿Siempre ha sido así? ¿Cómo fue su llegada en este sentido? ¿Le gusta tratar con ellos? ¿Se siente muy diferente a ellos?

- ¿Hay algún aspecto que haya influido en este sentido, como por ejemplo su manera de hablar? Cuando conversa con personas de Madrid de su entorno, ¿se siente incómodo por su manera de hablar? Si es así, ¿por qué es así? ¿Depende de la persona con la que hable? ¿Tiene la sensación de que es tratado como un extraño por su forma de hablar? ¿Cómo se siente? ¿Siente que se le puede estar juzgando negativamente por su manera de hablar? ¿Alguna vez ha preferido quedarse callado por este motivo? ¿Cuándo? ¿En qué ocasiones o hablando con qué personas?

- ¿Adapta su manera de hablar cuando habla con españoles para sentirse más integrado?

- Si no adapta su manera de hablar, ¿considera que los madrileños no le comprenden bien? ¿Ha vivido alguna situación difícil por este motivo, por ejemplo en el médico, en la farmacia, en la escuela? ¿Considera que es un problema suyo? ¿Tiene la sensación de que los madrileños consideran que es un problema de los ecuatorianos? ¿Cree que ellos tienen una predisposición positiva en este sentido? Si ha tenido alguna situación de este tipo, ¿se han disculpado los madrileños? ¿Han tratado de ayudarle?

- ¿Usted comprende bien la manera de hablar de los madrileños? $¿$ Tiene que hacer esfuerzos para entenderlos? ¿Cree que ellos hacen esfuerzos para que usted les pueda comprender mejor? ¿Ha tenido algún problema en este sentido, por ejemplo en el médico, en la farmacia, en la escuela? ¿Esto le hace sentir mal?

- ¿Cree que hay muchas diferencias entre los madrileños y los ecuatorianos? ¿Qué diferencias? ¿De qué tipo? ¿Culturales? ¿Qué es lo que más le llamó la atención al llegar?

- ¿Y en la manera de hablar? ¿Cree que existen diferencias entre la manera en que usted habla y la manera de hablar de los madrileños? ¿Por qué? ¿Cuáles son estas diferencias? ¿Reconoce a los madrileños por su manera de hablar?

- ¿Cuál de las dos formas de hablar tiene más prestigio para usted? ¿Y cuál considera que tiene más para los madrileños? ¿Por qué lo considera así? ¿ ¿Se lo han dicho en alguna ocasión? ¿Le han hecho algún comentario al respecto? ¿Cómo se siente cuando le dicen este tipo de cosas?

- ¿Cree que su forma de hablar está mal valorada por parte de los madrileños? 
Si es así, ¿por qué lo considera así?

- ¿Percibe algún rechazo por parte de los madrileños por su manera de hablar?

Si es así, ¿en qué aspectos lo percibe? ¿Puede decirme alguna situación concreta en la que haya sentido ese rechazo?

- ¿Percibe aceptación por parte de los madrileños por su manera de hablar? ¿En qué lo percibe?

- ¿Qué palabras de las que usted utiliza les sientan mal a los madrileños? ¿En qué lo nota? ¿Ha tenido usted algún problema por decir algo que en su país es normal y que en España no se utilice?

- ¿Hay alguna palabra que empleen los madrileños que le produzca vergüenza o que le parezca especialmente fuerte o grosera? Si es así, ¿cuál? ¿Qué palabra utiliza usted en su país para ese concepto? ¿Mantiene aquí esas diferencias? En general, ¿le parece grosera la manera en que se habla en Madrid?

\section{Trabajo}

- ¿Cómo consiguió su primer empleo en España? ¿Es el mismo que ahora? ¿Le gustó/le gusta? ¿Cuáles han sido sus trabajos aquí? ¿Y en su país?

- ¿Le costó mucho encontrar su primer trabajo? ¿Cómo fue? En general, ¿ha tenido problemas para encontrar trabajo?

- ¿Qué diferencias encuentra entre su trabajo de su país y su trabajo de aquí?

- ¿Qué le parecen los salarios? ¿Considera que su trabajo está bien remunerado?

- ¿Hay muchas diferencias con respecto a su país? ¿Considera que en España se trabaja mucho/poco? ¿Y en su país?

- ¿Cree que la forma en que usted habla puede influir negativamente para conseguir un trabajo?

Si es así, ¿adapta usted su forma de hablar cuando va a una entrevista de trabajo o cuando está trabajando con madrileños?

- ¿Cómo es la relación con sus compañeros de trabajo? ¿Se siente a gusto con ellos? ¿Se relaciona con ellos fuera del trabajo? ¿De dónde son? ¿Son españoles?

- ¿Tiene relación con otras personas extranjeras? ¿Y con otros ecuatorianos? 


\section{Vida cotidiana en España}

- ¿Qué hace en un día normal?

- ¿Qué diferencias encuentra entre su vida en su país y su vida en España?

- ¿Cómo se siente con la gente de España? ¿Trata mucho con los españoles o trata más con otros inmigrantes? ¿De dónde son?

- ¿Le gusta tratar con otros latinos? ¿Cree que el contacto con otros ecuatorianos/latinos le ayuda a mantener sus costumbres, su manera de hablar? ¿Frecuenta lugares que le ayuden a mantener el contacto con su país como locutorios, tiendas de productos típicos de su país, bares? ¿Son importantes para usted estos lugares? ¿Le ayudan a relacionarse con gente de su país? ¿Se siente más cómodo, más relajado cuando está con otros latinos? ¿Adapta su forma de hablar cuando está con otros latinos?

- ¿Le gusta el tipo de diversiones que tienen los españoles? En este sentido, ¿qué echa de menos de su país? ¿Participa de las diversiones que hay en España o sigue manteniendo las costumbres de su país?

- ¿Qué opina de las ceremonias y celebraciones de España? (bodas, entierros, fiestas...).

- ¿Usted es religioso? ¿Cree que los españoles son muy religiosos? ¿Cómo cree que viven los españoles la religión? ¿Se siente a gusto en este sentido en España?

\section{Familia e hijos}

- ¿Cómo está su familia aquí? ¿Cómo era su familia allí? ¿Cómo ve a la familia en España? ¿Difiere mucho del concepto de "familia" en su país?

- ¿Cuándo vino su mujer/marido? ¿Vino con usted? ¿Tiene hijos? ¿Vinieron ellos? ¿Cuándo?

- ¿Cómo es el trato con las esposas y los hijos en España?

- ¿Le parece España una sociedad machista?

- ¿Qué opina de la educación que se les da en España a los niños?

- ¿Cómo es la escuela en España? ¿Qué opina de ella?

- ¿Sus hijos nacieron aquí? ¿Cómo se encuentran ellos en España? ¿Cómo se encuentran ellos en la escuela? ¿Conocen Ecuador? ¿Están contentos aquí?

- ¿Cómo es su entorno? ¿Qué amistades tienen? ¿Con quién se relacionan? ¿Con españoles, con otros niños extranjeros, latinos, ecuatorianos?

- ¿Han tenido ellos algún problema de adaptación o de integración? 
- ¿Quieren volver a su país o les gustaría quedarse aquí?

- ¿Cómo hablan sus hijos: como usted o como los madrileños?

- ¿Cómo prefiere que hablen: como se habla en Ecuador o como se habla en Madrid? ¿Por qué? ¿Está contento por la forma en que hablan sus hijos?

- ¿Qué cosas dicen que usted no diga?

- ¿Cree que puede ser una ventaja para ellos hablar como se habla en Madrid? ¿Por qué? ¿Considera que es una ventaja para su adaptación?

- ¿Considera que, si no hablan como se habla en Madrid, podrían discriminarle los niños madrileños?

- Si sus hijos hablan como hablan los madrileños, ¿intenta de alguna manera que también aprendan determinadas palabras o elementos de la manera de hablar de Ecuador? ¿Cómo? ¿Por qué? ¿Piensa que es importante? ¿Por qué?

\section{Expectativas de futuro}

- ¿Tiene pensado volver a su país o le gustaría quedarse aquí? ¿Cuándo? ¿Por qué? ¿Qué es lo que más echa de menos?

- ¿Ha vuelto alguna vez en este tiempo? ¿Le gusta volver? ¿Por qué? ¿Qué siente cuando vuelve?

- ¿Qué expectativas tenía sobre España cuando decidió venir? ¿Han cambiado mucho esas expectativas?

- ¿Cómo cree que será su vida dentro de X tiempo en España? ¿Cómo le gustaría que fuera? ¿Le gustaría que cambiara algún aspecto? ¿Qué le gustaría que cambiara? ¿Por qué? ¿Cree que seguirá viviendo en Madrid? ¿Por qué?

- Si volviera a su país, ¿cree que hablaría según su manera de hablar en Ecuador o mantendrá la forma de hablar que emplea aquí?

- Si ha cambiado su manera de hablar y vuelve a Ecuador, ¿cree que allí le valorarán negativamente por su forma de hablar? 
ANEXO 2

\section{A. CUESTIONARIO SOBRE ACTITUDES LINGÜÍSTICAS INMIGRANTES}

Fecha:

Localidad:

Sexo:

Edad:

Estudios:

$\square$ Sin estudios $\square$ Estudios primarios $\square$ Estudios secundarios $\square$ Estudios universitarios

Ingresos mensuales:

$\square$ Sin ingresos $\square$ Menos de $600 € \square$ Entre 600 y $1200 € \square$ Entre 1200 y $2500 € \square$ más de $2500 €$

Lengua materna:

¿Qué otros idiomas habla usted?:

Lugar de nacimiento (localidad y país):

Fecha de la llegada a España:

Lugar de residencia actual:

Tiempo de residencia en la localidad:

Otros lugares de residencia en España:

Situación laboral:

Profesión en su país:

Profesión en España:

\section{Cuestionario}

1. ¿De dónde son la mayor parte de sus amistades en España?

$\square$ de España $\square$ de su país $\square$ de otros países

2. ¿Con qué frecuencia viaja a su país?

$\square$ más de una vez al año $\square$ una vez al año $\square$ menos de una vez al año

3. ¿Con qué frecuencia participa en actividades de ocio a las que asistan otros compatriotas?

$\square$ diariamente $\square$ semanalmente $\square$ mensualmente $\square$ sin frecuencia fija $\square$ nunca

4. ¿Con qué frecuencia escucha música de su país?

$\square$ diariamente $\square$ semanalmente $\square$ mensualmente $\square \sin$ frecuencia fija $\square$ nunca

5. ¿Con qué frecuencia sigue las noticias de su país?

$\square$ diariamente $\square$ semanalmente $\square$ mensualmente $\square$ sin frecuencia fija $\square$ nunca ¿A través de qué medios?

6. ¿Suele comprar a menudo en tiendas especializadas productos de su país? $\square$ diariamente $\square$ semanalmente $\square$ mensualmente $\square$ sin frecuencia fija $\square$ nunca

7. ¿Con qué frecuencia se comunica con familiares y amigos de su país? $\square$ diariamente $\square$ semanalmente $\square$ mensualmente $\square$ sin frecuencia fija $\square$ nunca

8. ¿Cree que ha incorporado a su manera de hablar algún rasgo de los madrileños?

Lengua y migración / Language and Migration 12:1 (2020) Monográfico, 39-81 Edición impresa: ISSN 1889-5425. Edición en línea: ISSN 2660-7166. @ Universidad de Alcalá 
9. Señale los dos aspectos que más le gusten de la manera de hablar de los madrileños.

1.

2.

10. Señale los dos aspectos que menos le gusten de la manera de hablar de los madrileños.

1.

2.

11. Indique su grado de acuerdo con las siguientes afirmaciones:

\begin{tabular}{|c|c|c|c|c|}
\hline & 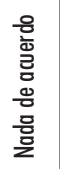 & 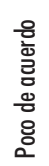 & 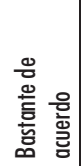 & 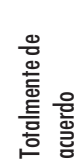 \\
\hline 1. La forma de vida de los madrileños es más interesante que la de mi país. & & & & \\
\hline 2. La cultura de mi país es más interesante que la española. & & & & \\
\hline 3. Intento mantener las costumbres de mi país. & & & & \\
\hline 4. Considero que mi integración en España es muy alta. & & & & \\
\hline 5. Procuro siempre que puedo mantener mi forma de hablar. & & & & \\
\hline 6. Prefiero que mis hijos mantengan la manera de hablar de sus padres. & & & & \\
\hline $\begin{array}{l}\text { 7. Hay muchas diferencias entre mi manera de hablar y la manera de } \\
\text { hablar de los madrileños. }\end{array}$ & & & & \\
\hline 8. Reconozco a un madrileño por su forma de hablar. & & & & \\
\hline 9. Los madrileños reconocen a mis paisanos por la forma de hablar. & & & & \\
\hline 10. A los madrileños les gusta el modo de hablar de mis paisanos. & & & & \\
\hline 11. He sentido rechazo de algunos madrileños por mi forma de hablar. & & & & \\
\hline 12. Los madrileños me han corregido al hablar en alguna ocasión. & & & & \\
\hline 13. Cuando voy a buscar un trabajo, intento hablar como los madrileños. & & & & \\
\hline $\begin{array}{l}\text { 14. Si hablo como los madrileños, puedo conseguir mejores puestos de } \\
\text { trabajo. }\end{array}$ & & & & \\
\hline $\begin{array}{l}\text { 15. Si hablo como los madrileños, podría conseguir que mejoren mis } \\
\text { relaciones sociales con ellos. }\end{array}$ & & & & \\
\hline $\begin{array}{l}\text { 16. Si hablo como los madrileños, podría tener oportunidad de relacionarme } \\
\text { con gente más interesante. }\end{array}$ & & & & \\
\hline 17. Si hablo como los madrileños, podría conseguir que me respetasen más. & & & & \\
\hline 18. Si hablo como los madrileños, podría obtener más beneficios sociales. & & & & \\
\hline $\begin{array}{l}\text { 19. Si mis hijos (si los tuviera) hablan como los madrileños, pueden mejorar } \\
\text { en la escuela. }\end{array}$ & & & & \\
\hline $\begin{array}{l}\text { 20. Si mis hiijos (si los tuviera) hablan como los madrileños, pueden } \\
\text { encontrar mejores oportunidades profesionales. }\end{array}$ & & & & \\
\hline $\begin{array}{l}\text { 21. Entre las distintas formas de hablar español, el que se habla en Madrid } \\
\text { es el más correcto. }\end{array}$ & & & & \\
\hline $\begin{array}{l}\text { 22. Cuando hablo con mis paisanos, me siento más cómodo hablando como } \\
\text { se habla en mi país. }\end{array}$ & & & & \\
\hline 23. Me gusta el castellano que se habla en Madrid. & & & & \\
\hline 24. Mi forma de hablar ha cambiado desde que estoy en España. & & & & \\
\hline $\begin{array}{l}\text { 25. Cuando hablo con familiares que están en mi país, me dicen que mi } \\
\text { forma de hablar ha cambiado. }\end{array}$ & & & & \\
\hline $\begin{array}{l}\text { 26. Mis familiares y compatriotas valorarían negativamente que mi forma de } \\
\text { hablar cambiara. }\end{array}$ & & & & \\
\hline 27. Si oigo hablar con acento de Madrid a algún compatriota, me parece ridículo. & & & & \\
\hline
\end{tabular}

Lengua y migración / Language and Migration 12:1 (2020) Monográfico, 39-81

Edición impresa: ISSN 1889-5425. Edición en línea: ISSN 2660-7166. @ Universidad de Alcalá 


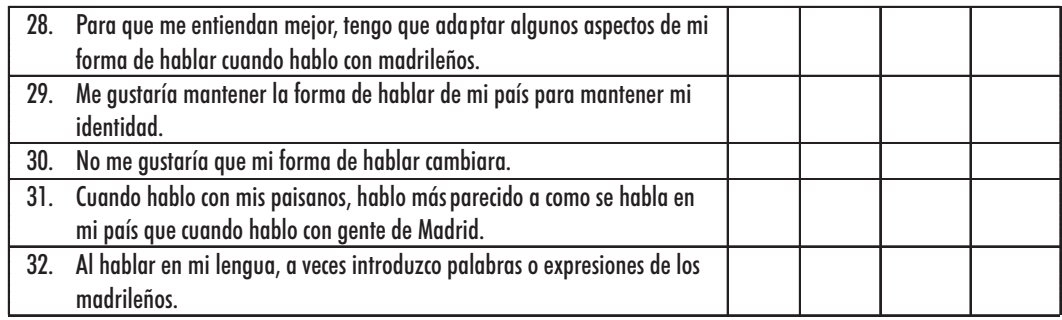

12. Sitúe en las siguientes escalas la consideración que le merece el modo de hablar de Madrid, comparándolo con el suyo propio. (Rodee con un círculo el número que más se aproxime a su opinión).

$\begin{array}{llllllllr}\text { Agradable } & 6 & 5 & 4 & 3 & 2 & 1 & \text { Desagradable } \\ \text { Áspera } & 6 & 5 & 4 & 3 & 2 & 1 & \text { Suave } \\ \text { Monótona } & 6 & 5 & 4 & 3 & 2 & 1 & \text { Variada } \\ \text { Sencilla } & 6 & 5 & 4 & 3 & 2 & 1 & \text { Complicada } \\ \text { Cercana } & 6 & 5 & 4 & 3 & 2 & 1 & \text { Distante } \\ \text { Blanda } & 6 & 5 & 4 & 3 & 2 & 1 & \text { Dura } \\ \text { Rural } & 6 & 5 & 4 & 3 & 2 & 1 & \text { Urbana } \\ \text { Lenta } & 6 & 5 & 4 & 3 & 2 & 1 & \text { Rápida } \\ \text { Divertida } & 6 & 5 & 4 & 3 & 2 & 1 & \text { Aburrida } \\ \text { Confusa } & 6 & 5 & 4 & 3 & 2 & 1 & \text { Clara } \\ \text { Bonita } & 6 & 5 & 4 & 3 & 2 & 1 & \text { Fea } \\ \text { Cortés } & 6 & 5 & 4 & 3 & 2 & 1 & \text { Descortés }\end{array}$

\section{B. CINTA ESTÍMULO}

Evaluación de grabaciones de 5 variedades de español (castellano, andaluz, canario, andina, caribeña; oral libre/lectura de texto)

1. Valore los siguientes aspectos sobre la pronunciación de la persona que acaba de escuchar. (Rodee con un círculo el número que más se aproxime a su opinión).

$\begin{array}{lllllllr}\text { Agradable } & 6 & 5 & 4 & 3 & 2 & 1 & \text { Desagradable } \\ \text { Áspera } & 6 & 5 & 4 & 3 & 2 & 1 & \text { Suave } \\ \text { Monótona } & 6 & 5 & 4 & 3 & 2 & 1 & \text { Variada } \\ \text { Sencilla } & 6 & 5 & 4 & 3 & 2 & 1 & \text { Complicada } \\ \text { Cercana } & 6 & 5 & 4 & 3 & 2 & 1 & \text { Distante } \\ \text { Blanda } & 6 & 5 & 4 & 3 & 2 & 1 & \text { Dura } \\ \text { Rural } & 6 & 5 & 4 & 3 & 2 & 1 & \text { Urbana } \\ \text { Lenta } & 6 & 5 & 4 & 3 & 2 & 1 & \text { Rápida } \\ \text { Divertida } & 6 & 5 & 4 & 3 & 2 & 1 & \text { Aburrida } \\ \text { Confusa } & 6 & 5 & 4 & 3 & 2 & 1 & \text { Clara } \\ \text { Bonita } & 6 & 5 & 4 & 3 & 2 & 1 & \text { Fea } \\ \text { Cortés } & 6 & 5 & 4 & 3 & 2 & 1 & \text { Descortéstés }\end{array}$


2. ¿Qué puesto de trabajo cree que tiene la persona que habla? $\square$ poco cualificado $\square$ bien cualificado $\square$ altamente cualificado

3. ¿Qué nivel de ingresos cree que tiene la persona que habla? $\square$ bajo $\square$ medio $\square$ alto

4. ¿Qué nivel de estudios cree que tiene la persona que habla? $\square$ sin estudios $\square$ primarios $\square$ secundarios 1 universitarios

5. En su opinión, la persona que habla es:

$\begin{array}{llllllllr}\text { Inteligente } & 6 & 5 & 4 & 3 & 2 & 1 & \text { Poco inteligente } \\ \text { Simpática } & 6 & 5 & 4 & 3 & 2 & 1 & \text { Antipática } \\ \text { Cercana } & 6 & 5 & 4 & 3 & 2 & 1 & \text { Distante } \\ \text { Culta } & 6 & 5 & 4 & 3 & 2 & 1 & \text { Inculta } \\ \text { Educada } & 6 & 5 & 4 & 3 & 2 & 1 & \text { Maleducada }\end{array}$

6. ¿De qué región de España (comunidad autónoma) cree que es la persona que habla?

7. ¿Conoce personas de ese país o región? En caso afirmativo, ¿qué opinión tiene sobre ellas?

8. ¿Qué opinión le merece la región (comunidad autónoma) de la que cree que es la persona que habla?

$\begin{array}{llllllll}\text { Avanzado } & 6 & 5 & 4 & 3 & 2 & 1 & \text { Retrasado } \\ \text { Divertido } & 6 & 5 & 4 & 3 & 2 & 1 & \text { Aburrido } \\ \text { Familiar } & 6 & 5 & 4 & 3 & 2 & 1 & \text { Extraño } \\ \text { Bonito } & 6 & 5 & 4 & 3 & 2 & 1 & \text { Feo }\end{array}$

9. ¿Qué opinión le merece la cultura de esa región (comunidad autónoma)?

$\begin{array}{lllllllr}\text { Innovadora } & 6 & 5 & 4 & 3 & 2 & 1 & \text { Tradicional } \\ \text { Rica } & 6 & 5 & 4 & 3 & 2 & 1 & \text { Pobre } \\ \text { Cercana } & 6 & 5 & 4 & 3 & 2 & 1 & \text { Distante } \\ \text { Interesante } & 6 & 5 & 4 & 3 & 2 & 1 & \text { Poco interesante }\end{array}$


ANEXO 3

\section{A. CUESTIONARIO SOBRE ACTITUDES LINGÜÍSTICAS MADRILEÑOS}

Fecha:

Localidad:

Sexo:

Edad:

Estudios:

$\square$ Sin estudios $\square$ Estudios primarios $\square$ Estudios secundarios $\square$ Estudios universitarios

Lugar de nacimiento (localidad y provincia):

Localidad de residencia:

Tiempo de residencia en la localidad:

Otras localidades en las que haya residido:

Profesión:

Situación laboral:

Ingresos mensuales:

$\square$ Sin ingresos $\square$ Menos de $600 € \square$ Entre 600 y $1200 € \square$ Entre 1200 y $2500 € \square$ más de $2500 €$

¿Qué idiomas habla?

¿Ha viajado por el extranjero?

A países hispanohablantes. No Sí ¿Con qué frecuencia?

A países no hispanohablantes. No Sí ¿Con qué frecuencia?

\section{Cuestionario}

1. ¿Pertenece a alguna asociación relacionada con los inmigrantes? En caso afirmativo, señale cuál.

2. ¿Tiene usted habitualmente relación profesional con inmigrantes? En caso afirmativo, ¿de qué nacionalidad son los inmigrantes? Describa brevemente en qué consiste esa relación.

3. ¿'Tiene usted amigos inmigrantes? En caso afirmativo, ¿̇de qué nacionalidad son? Señale brevemente desde cuándo.

4. Señale el grado de acuerdo con las siguientes afirmaciones

\begin{tabular}{|c|c|c|c|c|}
\hline & $\begin{array}{l}\text { 은 } \\
\text { 름 } \\
\text { 음 } \\
\text { 흠 } \\
\text { 을 }\end{array}$ & 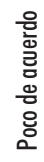 & 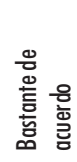 & 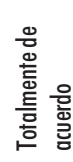 \\
\hline 1. Los inmigrantes son necesarios en la sociedad madrileña actual. & & & & \\
\hline 2. Hay demasiados inmigrantes en Madrid. & & & & \\
\hline 3. El número de inmigrantes que llega a Madrid está aumentando. & & & & \\
\hline 4. Los inmigrantes suponen una amenaza para el trabajo de los españoles. & & & & \\
\hline 5. Los inmigrantes contribuyen a solucionar problemas laborales en España. & & & & \\
\hline
\end{tabular}

Lengua y migración / Language and Migration 12:1 (2020) Monográfico, 39-81 Edición impresa: ISSN 1889-5425. Edición en línea: ISSN 2660-7166. () Universidad de Alcalá 


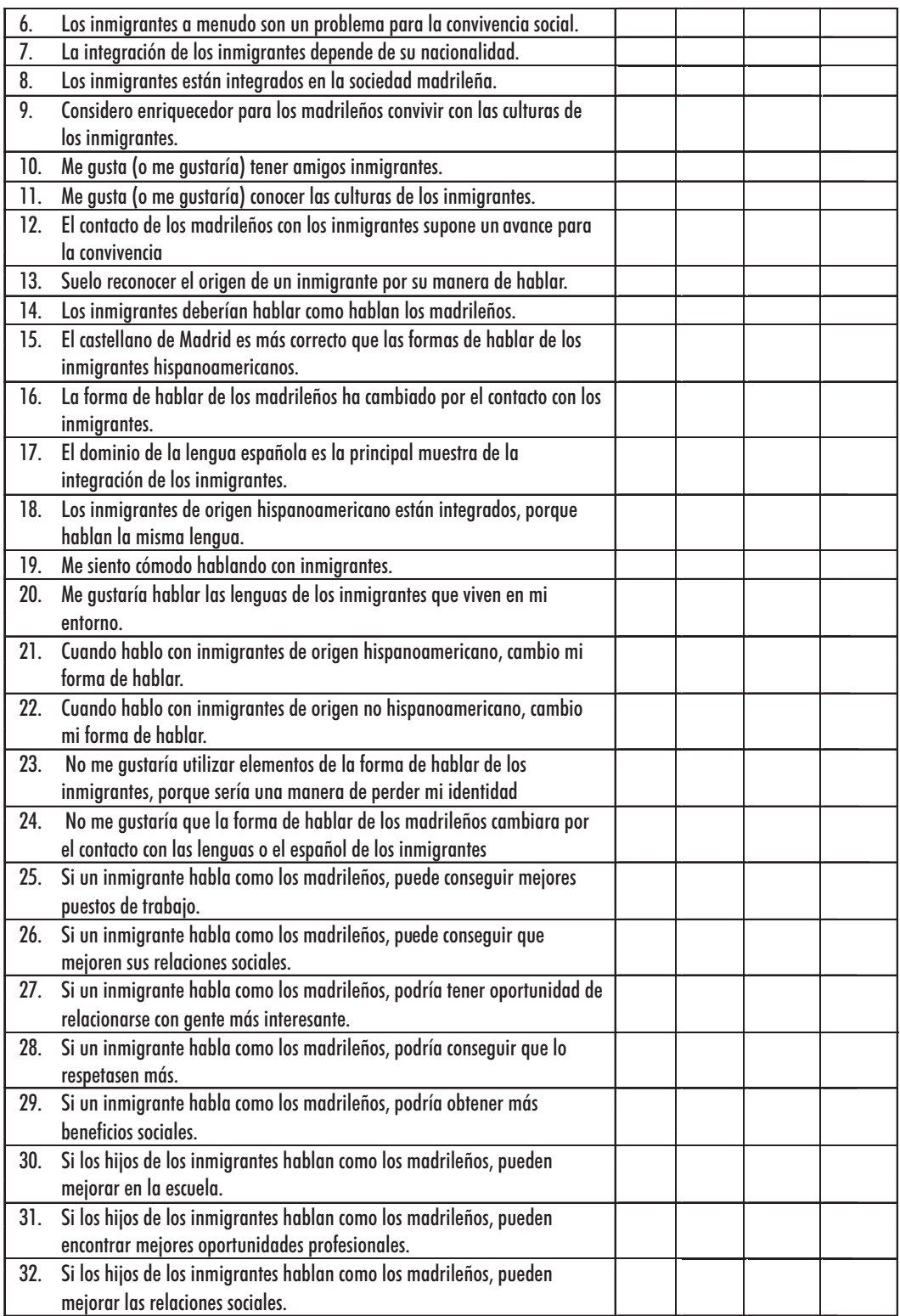

\section{B. CINTA ESTÍMULO}

- Evaluación de grabaciones de inmigrantes hablando español (rumano, polaco, brasileño, marroquí, + lengua neutra (inglés)

- Características del locutor: mujer; 30-40 años, nivel de estudios medio, llegado a España hace un año.

Lengua y migración / Language and Migration 12:1 (2020) Monográfico, 39-81

Edición impresa: ISSN 1889-5425. Edición en línea: ISSN 2660-7166. @ Universidad de Alcalá 
- Evaluación de variedades de español (colombiano, ecuatoriano, dominicano)

1. Valore los siguientes aspectos sobre la pronunciación de la persona que acaba de escuchar. (Rodee con un círculo el número que más se aproxime a su opinión).

$\begin{array}{llllllll}\text { Agradable } & 6 & 5 & 4 & 3 & 2 & 1 & \text { Desagradable } \\ \text { Áspera } & 6 & 5 & 4 & 3 & 2 & 1 & \text { Suave } \\ \text { Monótona } & 6 & 5 & 4 & 3 & 2 & 1 & \text { Variada } \\ \text { Cercana } & 6 & 5 & 4 & 3 & 2 & 1 & \text { Distante } \\ \text { Rural } & 6 & 5 & 4 & 3 & 2 & 1 & \text { Urbana } \\ \text { Divertida } & 6 & 5 & 4 & 3 & 2 & 1 & \text { Aburrida } \\ \text { Confusa } & 6 & 5 & 4 & 3 & 2 & 1 & \text { Clara } \\ \text { Cortés } & 6 & 5 & 4 & 3 & 2 & 1 & \text { Descortéstés }\end{array}$

2. ¿Qué puesto de trabajo cree que tiene la persona que habla? $\square$ poco cualificado $\square$ bien cualificado $\square$ altamente cualificado

3. ¿Qué nivel de ingresos cree que tiene la persona que habla? $\square$ bajo $\square$ medio $\square$ alto

4. ¿Qué nivel de estudios cree que tiene la persona que habla? $\square$ sin estudios $\square$ primarios $\square$ secundarios $\square$ universitarios

5. En su opinión, la persona que habla es:

$\begin{array}{llllllll}\text { Inteligente } & 6 & 5 & 4 & 3 & 2 & 1 & \text { Poco inteligente } \\ \text { Simpática } & 6 & 5 & 4 & 3 & 2 & 1 & \text { Antipática } \\ \text { Cercana } & 6 & 5 & 4 & 3 & 2 & 1 & \text { Distante } \\ \text { Culta } & 6 & 5 & 4 & 3 & 2 & 1 & \text { Inculta } \\ \text { Educada } & 6 & 5 & 4 & 3 & 2 & 1 & \text { Maleducada }\end{array}$

6. ¿De qué país cree que es la persona que habla?

7. ¿Conoce personas de ese país o región? En caso afirmativo, ¿qué opinión tiene sobre ellas?

8. ¿Qué opinión le merece el país de la que cree que es la persona que habla?

$\begin{array}{lllllllr}\text { Avanzado } & 6 & 5 & 4 & 3 & 2 & 1 & \text { Retrasado } \\ \text { Divertido } & 6 & 5 & 4 & 3 & 2 & 1 & \text { Aburrido } \\ \text { Familiar } & 6 & 5 & 4 & 3 & 2 & 1 & \text { Extraño } \\ \text { Bonito } & 6 & 5 & 4 & 3 & 2 & 1 & \text { Feo }\end{array}$

9. ¿Qué opinión le merece la cultura de ese país?

$\begin{array}{lllllllr}\text { Innovadora } & 6 & 5 & 4 & 3 & 2 & 1 & \text { Tradicional } \\ \text { Rica } & 6 & 5 & 4 & 3 & 2 & 1 & \text { Pobre } \\ \text { Cercana } & 6 & 5 & 4 & 3 & 2 & 1 & \text { Distante } \\ \text { Interesante } & 6 & 5 & 4 & 3 & 2 & 1 & \text { Poco interesante }\end{array}$

